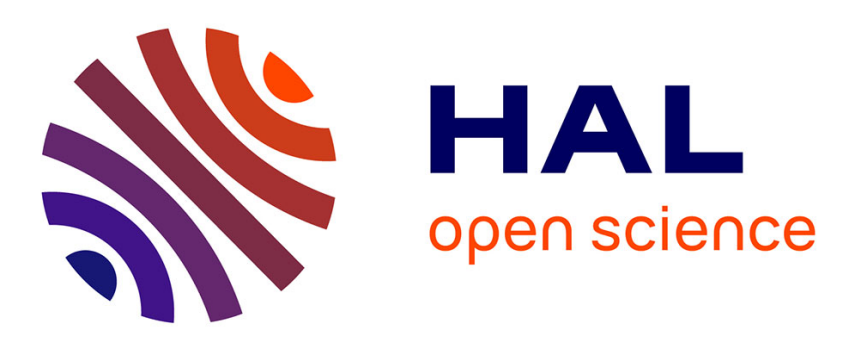

\title{
Tarski's Practice and Philosophy: Between Formalism and Pragmatism
}

Hourya Benis Sinaceur

\section{To cite this version:}

Hourya Benis Sinaceur. Tarski's Practice and Philosophy: Between Formalism and Pragmatism: What has Become of Them?. Sten Lindström; Erik Palmgren; Krister Segerberg; Viggo Stoltenberg-Hansen. Logicism, Intuitionism, and Formalism, Springer, 2009, 978-1-4020-8926-8 16. halshs-01122267

\section{HAL Id: halshs-01122267 https://shs.hal.science/halshs-01122267}

Submitted on 3 Mar 2015

HAL is a multi-disciplinary open access archive for the deposit and dissemination of scientific research documents, whether they are published or not. The documents may come from teaching and research institutions in France or abroad, or from public or private research centers.
L'archive ouverte pluridisciplinaire HAL, est destinée au dépôt et à la diffusion de documents scientifiques de niveau recherche, publiés ou non, émanant des établissements d'enseignement et de recherche français ou étrangers, des laboratoires publics ou privés. 


\section{Part III \\ Intuitionism and Constructive \\ Mathematics}




\title{
Tarski's Practice and Philosophy: Between Formalism and Pragmatism
}

\author{
Hourya Benis Sinaceur
}

\section{Some General Facts About Formalism}

\subsection{Definitions}

The term 'formalism' may have at least three different meanings. First, 'formalism' can be understood as referring to a mathematical way of operating. A formalist way of doing mathematics shows how one can get new and innovative results from the mere inspection of symbolic expressions used or coined for mathematical entities or properties. In this wide sense, which is internally connected with a permanent aspect of mathematical practice, one usually speaks of a «formal» rather than of a «formalist» point of view. Leibniz was a great supporter of such a view, promoting symbols and diagrams, be they arithmetical (differential operator, series, determinants) or geometrical (objects of the analysis situs), as one way of the «ars inveniendi $\gg$. This point of view is highly represented, from the XIXth century onwards, by the study of mathematical structures defined by axiom systems. Mathematical structuralism aims at more generality, increasing simplicity and unification, deeper understanding and richer fruitfulness. In a second meaning, 'formalism' means a philosophical attitude, which seeks an answer not to the question: «how can one do mathematics in a general and very efficient way?» but to the question: «how or on what to ground mathematical practice?» Mathematical structuralism aims at grounding mathematics on the most abstract and general structures, such as those laid for arithmetic or set theory. For instance, Dedekind based the theory of whole numbers on an abstract theory of «simply infinite systems» which presents $N$ as an ordered set satisfying some characteristic conditions. The third and more specific sense of 'formalism' comes from Hilbert's metamathematics, which combines logical analysis of mathematical procedures with philosophical views on the foundations of mathematical practice. This third sense is linked to Hilbert's concern

H.B. Sinaceur $(\bowtie)$

IHPST (Institut d'Histoire et Philosophie des Sciences et des Techniques),

CNRS-Université Paris 1

e-mail: sinaceur@canoe.ens.fr 
with formal systems of mathematical theories, to his syntactic study of mathematical proof [Beweistheorie], and, notably, to his search for consistency proofs which would secure the soundness of mathematical reasoning against the paradoxes of set theory and would permit to avoid restrictions on classical logic.

\subsection{Hilbert's Formalism: Words and Subject. The Paradigm of Algebra}

In his essays on the foundations of mathematics, Hilbert did use the German word 'Formalismus', but not to characterize a philosophical attitude towards questions on the nature of mathematical objects or practice. 'Formalismus' meant 'formal system' or 'formal language', both technical concepts of mathematical logic. Sometimes, Hilbert used the word 'Formalismus' as meaning 'formalization', which is again a technical process of mathematical logic. ${ }^{1}$ Thus 'Formalismus' is either the result of a process of formalization or the process itself. Even when Hilbert alluded in his 1931 essay to Brouwer's «reproach of formalism», he took 'Formalismus' only in the technical sense and explained that the use of formulas, i.e. formalization, is a necessary tool of logical investigation.

Mostly, 'Formalismus' is contrasted and correlated with 'Inhaltlichkeit' or with 'inhaltliche Überlegungen', and there may be naturally different formalisms or formalized constructions of the same content. The relationship between formal processing and informal thinking was nevertheless considered as an epistemological problem, just as the consistency problem. ${ }^{2}$ And just as for the consistency problem, Hilbert aimed at a logical-mathematical solution, which would make obsolete the epistemological way of questioning and answering. I will briefly sketch this solution below, in 1.4. However, one may note that philosophers of mathematics did not stop until now to be concerned with the relationship between formal setting and content.

Otherwise, Hilbert used the German word 'Formeln' to speak of mathematical formulas. He distinguished between numerical formulas, such as $2+3=3+2$ or $2<3$, and formulas involving variables, namely literal expressions of algebra, such as $a+b=b+a$ or $a<b$. The first ones convey a content which is immediately understandable, while the latter, the «right» formulas, are 'selbständige formale Gebilde' which have no immediate meaning and are nothing but $\ll$ objects submitted to the application of our rules». ${ }^{3}$ Numerical formulas are formalized through algebraic formale Gebilde, which constitute the customary formal part of mathematics. Being entirely determined by definite rules, the formal part of mathematics is con-

\footnotetext{
${ }^{1}$ Hilbert [29], in Hilbert [36, p. 153]; [30], in Hilbert [36, pp. 165, 170]; [33, pp. 67, 77]; [35, p. 493].

${ }^{2}$ Hilbert [29], in Hilbert [36, p. 153]. As Wolenski suggested to me, it is worth recalling that the contrast between 'form' and 'content' (Form, Inhalt) was very popular in Neo-Kantian philosophy, which was very influential at the break of XIX/XX century.

${ }^{3}$ Hilbert [33, p. 72] (my translation).
} 
trollable. Hilbert argued that the «formaler Standpunkt», eminently illustrated by algebraic methods, should be expanded to all of mathematics.

\begin{abstract}
«In algebra we consider the expressions formed with letters to be independent objects in themselves, and the propositions of number theory, which are included in algebra, are formalized by means of them. Where we had numerals, we now have formulas, which themselves are concrete objects that in their turn are considered by our perceptual intuition, and the derivation of one formula from another in accordance with certain rules takes the place of number-theoretic proof based on content.

Thus algebra already goes considerably beyond contentual number theory.» ${ }^{4}$
\end{abstract}

As a parallel result of this extension, Hilbert upheld a «new formal standpoint», 5 which suited the finitistic building of proof theory. 'Formeln' came then to be contrasted with the usual mathematical sentences and to designate the corresponding counterpart of the latter in some convenient formalism; ${ }^{6}$ they became also «ideal sentences» in a sense analogical to that of Kummer's ideal numbers.

In Hilbert's early views the formal standpoint was conceived of as a conceptual one and opposed to the algorithmic point of view, supported at that time by Paul Gordan and, to some extent, by Leopold Kronecker. It was then Gordan's calculating methods which were considered as «absolute formalism» in the sense that «formulas were the indispensable supports of the formation of his thoughts, his conclusions and his mode of expression $\gg .^{7}$ Hilbert balanced out the exclusive use of symbolic calculations and developed an abstract way of thinking and proving that he notably introduced in the theory of algebraic invariants. As we know, Hilbert found out an indirect (through reductio ad absurdum) and general (valid for every system of algebraic forms of $n$ variables) proof of the finite basis theorem (1888). Hilbert did not calculate, for each $n$, the effective number $k$ of the basic invariants, but showed the existence of a finite basis for any system and for all $n$, by showing that the assumption of the negation of the statement asserting this existence leads to contradictions. Thus, very early in his career, Hilbert advocated the formal point of view first and foremost because it is conducive to general proofs, which make salient structural properties of the problem under consideration. Moreover, the clear distinction between meaning and structure, objects and rules permits to handle uniformly and at once objects of different kinds. Now, the internal efficiency of the formal point of view as well as the applicability of mathematical structures to extra-mathematical phenomena are recognized as valuable. But, from the philosophical standpoint, what is at stake in axiomatic definitions and in structural existence proofs is the meaning of mathematical existence. Does existence follow from the supposed compatibility of some selected axioms as long as no contradiction appears in their consequences?

\footnotetext{
${ }^{4}$ Hilbert [33, pp. 71-72]; English translation in van Heijenoort [76, p. 469]. The standpoint of formal algebra is presented in a different way in Hilbert and Bernays [37, pp. 29-32]: the elementary algebra, defined as the elementary theory of rational functions with integer coefficients, is included in the domain of elementary contentual inference.

${ }^{5}$ Hilbert [30], in Hilbert [36, p. 168].

${ }^{6}$ Hilbert [30, p. 174]; [31, p. 179]; [32, p. 175]; [33, p. 66].

${ }^{7}$ Reid [50, p. 30].
} 
Or are existential statements «empty inventions of logicians ${ }^{8}$ as long as we don't have an actual realization?

\subsection{Brouwer's Criticism}

Brouwer, who stood up for the second opinion, was the one who used for the first time the word 'formalism' as denoting the first opinion. In a 1909 review of Mannoury's Methodologishes und Philosophishes zur Elementar-Mathematik, Brouwer wrote that $\ll$ the formalist conception recognizes no other mathematics than the mathematical language and it considers it essential to draw up definitions and axioms and to deduce from these other propositions by means of logical principles which are also explicitly formulated beforehand. This has two consequences..., namely the priority of infinite over finite numbers and the belief in higher cardinalities than that of the continuum». ${ }^{9}$ In his famous 1912 essay, Brouwer added other considerations, the analysis of which shows that he took formalism as purely and simply antithetic to his intuitionism. ${ }^{10}$ By the label 'formalism', Brouwer referred to a global philosophical attitude involved in classical methods of analysis as well as in set theory and in modern axiomatic theories, which use the language and the means of symbolic logic. According to Brouwer [9], formalism encompasses three main assumptions. First, formalism admits the existence of an entity on the grounds of its supposed non-contradictory definition. Such an existence, says Brouwer, is merely a linguistic existence, which corresponds to the method of posing meaningless axioms and deducing from meaningless relations some other meaningless relations in the language of symbolic logic. The second point is a consequence of the former: being meaningless, formalist assertions miss intuitive thinking and put forward logical support for self-evident principles, such as the principle of complete induction. In particular, the aim at consistency-proofs is anchored in a logical, i.e. a non-mathematical, conviction of legitimacy. Using the term 'conviction', which is Brouwer's word, ${ }^{11}$ means that even logical procedures may be rooted in (or supported by) a subjective belief. That is a harsh criticism against the supposed absolute objectivity of logic, which formalists put in contrast with subjective intuition. Moreover, and more seriously, the aim at consistency-proofs leads to a vicious circle, as Poincaré [49] already pointed out. Last but not least, the third point highlighted by Brouwer is the Platonist assumption of a universe of mathematical entities,

\footnotetext{
${ }^{8}$ H. Weyl [80], English translation in Mancosu [44, p. 133].

${ }^{9}$ Brouwer [14, p. 121].

${ }^{10}$ Brouwer [9], in Brouwer [14, pp. 123-137].

11 Brouwer [14, p. 125]: «It is true that from certain relations among mathematical entities, which we assume as axioms, we deduce other relations according to fixed laws, in the conviction that in this way we derive truths from truths by logical reasoning, but this non-mathematical conviction of truth or legitimacy has no exactness whatever and is nothing but a vague sensation of delight arising from the knowledge of the efficacy of the projection into nature of these relations and laws of reasoning» (my emphasis).
} 
subsisting independently of our thought and, so to speak, ready to be structured according to the laws of classical logic and set theory.

Brouwer took just the opposite views on the three points: he advocated intuition as the original material source and justification of mathematical practice; he argued that the language is a «non-mathematical auxiliary» for helping memory or conveying communication (along with misunderstanding); he rejected the Platonist static view, defending a dynamic conception in which an entity exists for a mathematician if it is actually constructed by some effective process. According to Brouwer, formalist purported foundations of mathematical laws on the axiomatic method are nothing but mere linguistic explanations, devoid of content, which, as such, don't really (materially) explain anything. By contrast, intuitionism explains the accuracy of mathematical reasoning by the material self-development of human mind from one original insight. The original insight [Urintuition] is the a priori insight of time, from which is derived, by «abstraction $\gg,{ }^{12}$ the first mathematical insight, namely the intuition of the number 2 and, step by step, the intuition of whole numbers and of any mathematical construct grounded on whole numbers. The intuition of two-ity is the fundamental phenomenon of mathematical thinking.

It is worth noting that Brouwer acknowledged the mediating role of mathematical abstraction in the very first intuitive process. Mathematical abstraction produces indeed the very first empty form, which constitutes the first substratum, «as basic intuition». That is to say that Brouwer did not oppose intuition to form in the substantial mathematical process. It is quite the contrary, as it is clear from the passages quoted in footnote 12. Brouwer did naturally not reject the formal way of practice. What he rejected was locating the justification of mathematical substance in symbolic schemas and formal deductions, which are, according to him, only an external dressing. Brouwer rejected also formalism, not as a mathematical way, but as philosophy, or, more accurately as mathematical project to solve philosophical

12 See Brouwer [11], in Brouwer [14, pp. 418-419], English translation in Mancosu [44, p. 46]: $\ll$ Mathematical action can only reach its full development at the higher stages of civilization when mathematical abstraction comes into play. By means of mathematical abstraction man strips twoity of its material content and retains it as an empty form, the common substratum of all twoities. This common substratum of all two-ities forms the Primordial Intuition of Mathematics (die Urintuition der Mathematik), which in its self-unfolding also introduces the infinite as a thoughtreality and produces the collection of natural bumbers..., as well as the real numbers, and finally the whole of pure mathematics» (Brouwer's emphasis).

See also Brouwer [12], in Brouwer [14, p. 482]: «Mathematics comes into being, when the two-ity created by a move of time is divested of all quality by the subject, and when the remaining empty form of the common substratum of all two-ities, as basic intuition of mathematics, is left to an unlimited unfolding, creating new mathematical entities in the shape of predeterminately or more or less freely proceeding infinite sequences of mathematical entities previously acquired, and in the shape of mathematical species i.e. properties supposable for mathematical entities previously acquired and satisfying the condition that if they are realized for a certain mathematical entity, they are also realized for all mathematical entities which have been defined equal to it» (Brouwer's emphasis). 
problems. ${ }^{13} \mathrm{He}$ especially disputed the prominent role that formalists, as well as logicists, gave to logic in the foundations of mathematics. He summed up the debate between formalism and intuitionism in the following ironic words: «The question where mathematical exactness does exist, is answered differently by the two sides; the intuitionist says: in the human intellect, the formalist says: on paper.» ${ }^{14}$

Three observations need to be made. Firstly, just as it is a mistake to believe that, in Brouwer's mind, intuition excludes abstraction, it would be wrong to trust the popular image of formalism and to believe that for «formalist» mathematicians intuition plays no role at all. From the structural point of view, it is for the sake of a flawless rigor that intuition must be submitted to a logical and axiomatic analysis, as, for instance, Dedekind did for Number theory ${ }^{15}$ and Hilbert for Euclidean geometry. ${ }^{16}$ Intuition is admitted as giving the matter to be analyzed, criticized, and generalized, but this chronological priority does not legitimate an ontological or epistemological primacy.

Second remark. The belief in a pre-existent universe of mathematical objects characterizes more sharply logicism than formalism. Now in his 1912 essay, Brouwer did not even mention logicism as a separate point of view. According to the title, he distinguishes only two contrary options: formalism and intuitionism, which, he thinks, cannot understand each other, because «they do not speak the same language $\gg$. And indeed, grounding both on the laws of classical logic, and in particular on the principle of excluded middle, logicism and formalism speak, in Brouwer's opinion, the same language. In the 1909 review Brouwer mentioned among the formalists Dedekind, Peano, Russell, Hilbert and Zermelo. In a later paper he added Cantor and Couturat to the list:

$\ll \ldots$ the Old Formalist School (Dedekind, Cantor, Peano, Hilbert, Russell, Zermelo,

Couturat), for the purpose of a rigorous treatment of mathematics and logic (though not

${ }^{13}$ Kreisel [42, p. 158], observed similarly that «the real opposition between Brouwer's and Hilbert's approach was not at all between formalism and intuitive mathematics, but between the conception of what constitutes a foundation».

14 Brouwer [14, p. 125].

15 See [17, pp. 99-100]: «How did my essay [Was sind und was sollen die Zahlen?] come to be written? Certainly not in one day; rather it is a synthesis constructed after protracted labor, based upon a prior analysis of the sequence of natural numbers just as it presents itself, in experience, so to speak, for our consideration. What are the mutually independent properties of the sequence $N$, that is, those properties that are not derivable from one another but from which all others follow? And how should we divest these properties of their specifically arithmetic character so that they are subsumed under more general notions and under activities of the understanding without which no thinking is possible at all but with which a foundation is provided for the reliability and completeness of proofs and for the construction of consistent notions and definitions?».

${ }^{16}$ See Hilbert's Grundlagen der Geometrie, 1968, p. 1: «Die Aufstellung der Axiome der Geometrie und die Erforschung ihres Zusammenhanges ist eine Aufgabe, die seit Euklid in zahlreichen Abhandlungen der mathematischen Literatur sich erörtet findet. Die bezeichnete Aufgabe läuft auf die logische Analyse unserer räumlichen Anschauung hinaus» (my emphasis). See Webb's valuable comments on Hilbert's geometrical methods, Webb [77, Chapter III]: in short, Hilbert did not eschew space intuition, he made the axioms of geometry more explicit $\ll$ in order to determine both explicit and implicit uses of space intuition» (p. 110). 
for the purpose of choosing the subjects of investigation of theses sciences) rejected any element extraneous to language and logic. ${ }^{17}$

It is clear that Brouwer made no difference between logicists and formalists. There were two major reasons for gathering them under the same label. First, logicists and formalists both distrusted intuition as being an unreliable access to mathematical objects and a shaky ground for mathematical practice. Second, they both developed projects that were intended to ground mathematics on logic, logic being understood as yielding schemas of correct derivation for a formal theory, especially that of natural numbers, the base of the rest. Hilbert's aim was to establish a simultaneous foundation of the laws of arithmetic and logic. ${ }^{18}$ But, while logicists believed that mathematical entities were discovered by purely logical thought, formalists advocated explicitly the free creation or construction of new concepts [Begriffsbildungen,${ }^{19}$ even of old familiar notions such as that of whole numbers. For Dedekind indeed numbers are $\ll$ free creations of the human mind», which $\ll$ serve as a means of apprehending more easily and more sharply the difference of things $\gg .{ }^{20}$ They are also objective instruments for grasping the multiplicity. In a similar spirit, and as a justification for the transfinite numbers, Cantor argued that «the human mind has an unlimited ability to progressively construct classes of numbers ... with increasing powers (Mächtigkeiten) ${ }_{.}{ }^{21}$ Here again, the mathematical universe (including infinite sets) is originating from the human mind. Hilbert supported this view: in his opinion the theory of transfinite numbers was «the most admirable flower of the mathematical intellect and in general one of the highest achievements of purely rational human activity». ${ }^{22}$

Rigorously speaking, this conception of a creative mind would entail a philosophical subjectivism, i.e. the conception of a subjective existence of those created concepts. Now, «subjective existence» might mean existence in our mind, or existence dependent of our mind. Formalists generally choose the second (weaker) meaning while Brouwer assumed the first too. ${ }^{23}$

\footnotetext{
${ }^{17}$ Brouwer [13, p. 508] (Brouwer's emphasis).

${ }^{18}$ Sieg [54] showed how Hilbert moved progressively from «a critical logicism through a radical constructivism toward finitism».

19 Typical expression of Hilbert's style. See, for instance [28, p. 183]; [32, p. 170]; [33, p. 65] (translated by [ways of] «forming notions» and by «mathematical definitions» in van Heijenoort [76], respectively on p. 376 and p. 464; the literal translation: «concept-formations» of Mancosu [44, p. 189], seems preferable to me).

${ }^{20}$ Grounding on the text quoted in footnote 15 , one must precise that what Dedekind considered as «a free creation of the human mind» were not the familiar numbers of our naive arithmetical experience, but the «shadowy forms» that Dedekind was making free from any particular content and which «are always the same in all ordered simply infinite systems, whatever names may happen to be given to the individual elements» (Dedekind [16], Definition 73).

${ }^{21}$ Cantor [15, p. 177] (Cantor's emphasis).

${ }^{22}$ Hilbert [32, p. 167], in van Heijenoort [76, p. 373].

${ }^{23}$ See the passages quoted above in footnote 12 and the following excerpt: «The fullest constructional beauty is the introspective beauty of mathematics, where instead of elements of playful causal acting, the basic intuition of mathematics is left to free unfolding. This unfolding is not
} 
Dedekind and Hilbert rejected no less vigorously than the logicists (Bolzano or Frege) subjectivism as meaning existence only in our mind. ${ }^{24}$ They conceived of axiomatic definitions as objective structural laws of mathematical processes in concordance with the laws of thought. Such a conception fits the Kantian view according to which the human mind [Verstand] is entitled with the legal power of organizing experience: mathematical concepts depend on the structure of the human mind and they help to organize the phenomenal world. ${ }^{25}$ But, while focusing on what they accepted as laws of mind, formalists generally did not accept the apriority of space and time as the formal setting making experience possible through the application of categories. - On his side, Brouwer abandoned the apriority of space but advocated resolutely the apriority of time. - Formalists admitted at the same time that mathematical concepts were created (constructed) rather than discovered and that the construction was neither arbitrary nor conventional but corresponded to some objective phenomenal connections. I would say that the creationist view was bound with the assumption of the objective adequacy of mind with the physical world. Such an adequacy, if it holds, leads to assume a kind of immediate consistency of the created concepts, which become questionable only when some contradiction appears in their consequences.

Third remark. Denying a foundational status to intuition, as Hilbert did firstly, is hardly compatible with a coherent and strict Platonism (such as that one defended by Gödel). - But associating anti-Platonism with foundational intuition, as Brouwer did, is not less problematic, unless intuition does not mean intuition of something exterior to the mind and reduces to mere introspection. An implication accepted by Brouwer, as I recalled right above. - In fact, matters were (and are) really complicated and the difficulties inherent to connecting a one-sided and clear-cut philosophical attitude with the multi-faceted mathematical practice have been explained in Bernays' famous essay on Platonism in mathematics. ${ }^{26}$ Developing a criticist remark passed by Hilbert on Frege's «extreme conceptual realism», ${ }^{27}$ Bernays distinguished two kinds of Platonism: (1) the restricted one, which considers abstract entities as nothing but a sort of «ideal projection of a domain of thought» (a precise explanation of the meaning of this expression would lead to some difficulties, that we do not want to address in this paper); (2) the extreme Platonism in the sense of a conceptual realism, which postulates an independent world of ideas containing all

bound to the exterior world, and thereby to finiteness and responsibility», Brouwer [14, p. 484] (my emphasis).

${ }^{24}$ Hilbert [33, p. 80], in van Heijenoort [76, p. 475]: «it is part of the task of science to liberate us from arbitrariness, sentiment, and habit and to protect us from the subjectivism that already made itself felt in Kronecker's views and, it seems to me, finds its culmination in intuitionism».

${ }^{25}$ Such a view leads often to some kind of instrumentalism. Since formalists generally reject the idea of an ontological foundation for mathematics, they tend to support a positivistic justification, according to which mathematical methods are epistemological tools in coping with the empirical world.

${ }^{26}$ Bernays [7]. Reprint in P. Bernays, Philosophie des mathématiques, Paris, Vrin, 2003, pp. 83-104.

${ }^{27}$ Hilbert [30, p. 162]. 
the objects and relations of mathematics. According to Bernays, Russell's antinomy ruined only the extreme Platonism (which was supported by Bolzano and Frege, and not by Dedekind or Hilbert). The minimal assumption of a restricted Platonism is to admit the set of natural numbers. Bernays observed that for some theories even this minimal assumption is not necessary: Kronecker introduced algebraic numbers without supposing the totality of whole numbers. But for other domains, such as infinitesimal analysis or function theory, the minimal assumption is needed. The strongest assumptions of Platonism are made in Cantorian set theory.

The fact is that, in his 1912 paper, Brouwer explicitly aimed to challenge the validity of the axioms of set theory stated by Zermelo in 1908. It was therefore natural that Brouwer associated Platonism, a kind of which supported, at least tacitly, the underlying universe of sets, with the general formal point of view. Now, working with actual infinite sets does not necessarily means that one believes that they exist prior to and independently of their being thought. A formalist, even if he is a set-theorist, need not to support an extreme Platonist view of pre-existing sets; he may content himself with some restricted view. But certainly, applying to infinite sets the principle of excluded middle is rightfully questionable in any case. Brouwer did not reject the infinite. He simply understood it as a «thought-reality» (se above, footnote 12) and he did not accept higher cardinalities than those of natural numbers and real numbers. But, he definitely rejected the general use of the principle of excluded middle, which has been classically used by mathematicians for centuries, and he replaced the static «spatial» conception of sets involved in it with a dynamic self-unfolding of spreads based on the apriority of time.

Although Brouwer's [9] paper did not make explicit reference to Hilbert, the attack against Hilbert's 1904 (published in 1905) paper on the foundations of logic and arithmetic was very clear. In particular, Brouwer repeated Poincaré's devastating argument [49] against the admission of the principle of complete induction as an axiom, instead of accepting it as intuitively evident.

\subsection{Hilbert's Defense of Formalism}

As is well known, Hilbert took Poincaré's and Brouwer's objections seriously and he associated the latter with Kronecker's reductionism to whole numbers. From 1918 to 1931, he published a series of essays, in which he introduced a «new mathematics», namely metamathematics, and developed technically and philosophically his famous finitistic program. It is not my purpose to enter in the technical details of this program ${ }^{28}$ and its subsequent reorientations. I would like only to point out some philosophical modifications it involved. ${ }^{29}$ Hilbert supported indeed

\footnotetext{
${ }^{28}$ See in particular the recent paper by R. Zach [86] on $\varepsilon$-calculus and consistency proofs in Hilbert's school.

${ }^{29}$ See Sieg [54] for a thorough analysis of Hilbert's unpublished notes of lecture courses from 1917 to 1922.
} 
a new formal point of view, which incorporated what he called «the constructivity principle» and some other intuitionistic insights in a much more systematic and radical «formalism» than that (1905) which aroused Brouwer's polemic notion of formalism. Brouwer's criticism acted in a performative way and pushed Hilbert to present logical inferences as «purely formal operations with letters $»^{30}$ and to play fully the formula game in a constructive way.

a) Hilbert was urged by Brouwer's and Weyl's objections to make precise the concept of formal system through a kind of material implementation. He considered that one must have something primitive and irreducible to begin with. $\mathrm{He}$ then changed his mind about intuition and logic and accepted to give intuition a basic role in the formal treatment. From 1922 onwards, he gave up Frege's and Dedekind's idea to provide for arithmetic a foundation that would be independent of all intuition and experience and he claimed that «as a condition for the use of logical inference and the performance of logical operations, something must already be given to our faculty of representation, certain extra-logical concrete objects that are intuitively present as immediate experience prior to all thought $\gg .{ }^{31}$ Thus, Hilbert admitted that the mathematician starts with an intuitive notion of natural numbers, what was Kronecker's, Poincaré's and Brouwer's common claim. However, what he regarded as intuitive was not a familiar or naïve notion but a finite stock of symbols given to spatial perception and having, in themselves, no meaning at all. The objects of (formal) arithmetic are not numbers but numerals, mere shapes or types of the actual signs written down on a sheet of paper. The sign ' 1 ' is a number as well as any finite sequence beginning and ending with 1 provided that the sign ' + ' is placed between two successive 1 . Thus, instead stating by an existence axiom that «each number has a successor», Hilbert introduced a progressive construction. Answering Poincaré's objection Hilbert distinguishes this combinational way to construct finite numbers as numerals from the principle of complete induction; the latter is a formal principle based on the induction axiom, which uses the general concept of whole number, while the former is a contentual [inhaltlich] composition. Hilbert maintained however that the formal principle, along with the other axioms of his formal system for natural numbers, has to be justified by a consistency proof. ${ }^{32}$

${ }^{30}$ Sieg [54, p. 9]. Sieg notes that this presentation requires «a formal language (for capturing the logical form of informal statements), the use of a formal calculus (for representing the structure of logical arguments), and the formulation of 'logical' principles (for defining mathematical objects)». Sieg highlights Hilbert's and Bernay's contribution to the creation of modern mathematical logic (pp. 11-12).

${ }^{31}$ Hilbert [30, p. 162]; [32], in van Heijenoort [76, p. 376]; [33], in van Heijenoort [76, p. 464].

32 Weyl [81] gave right to Poincaré: even if a consistency proof could justify the formal principle, it would not justify the intuitive one. Therefore one need not express mathematical induction as an axiom; one may just make its self-evidence and primarity explicit and accept it as a characteristic mark of contentual mathematical thought [76, p. 483]. In a similar way, Brouwer [10] pointed out again the circularity of the endeavor of justifying the formal proposition by a consistency proof, «since this justification rests upon the (contentual) correctness of the proposition that from the 
The trick of the new formal point of view was to apply to mere types of signs a contentual constructive process and, thus, to reverse the traditional relationship between formal and content: the perceptible object is formal and it is submitted to a contentual process. Mathematical thoughts, in the customary sense, are mirrored by concretely exhibited formulas, which are either primitive sentences or sentences provable, at some stage, from those primitive ones, and the whole of mathematics is duplicated by a stock of formulas. Besides mathematical signs, those formulas contain logical signs, which are, too, divested of all meaning. In turn, proofs are indeed perceptible arrays or sequences of formulas, which concretely present the formal images of customary mathematical inference so that «contentual inference is replaced by manipulation of signs according to rules $\gg .{ }^{33}$ Thus, Hilbert confirmed Brouwer's account of formalism ${ }^{34}$ and went even further: he understood insight as physical perception and formalism as a mechanistic operating with mere signs, formulas and arrays. The latter are indeed, according to his new point of view, the concrete and surveyable objects of metamathematics, which is «the contentual theory of formalized proofs $»^{35}$ and which would use only contentual arguments for establishing the consistency of the formalized system of arithmetic. The contentual character ultimately rests, on the one hand, upon Hilbert's conviction that metamathematical induction, operating on finite existing totalities, was contentual, ${ }^{36}$ just as intuitive composition and decomposition of numerals, and, on the other hand, upon the fact that the consistency proof amounts to show that one cannot derive the formula $0 \neq 0$ in the system under consideration, «a task that fundamentally lies within the province of intuition $\gg .{ }^{37}$ Hilbert wanted to renounce neither Cantor's paradise nor Aristotle's laws of logic. He aimed at justifying them contentually and by finitistic, i.e. strictly constructive, means. ${ }^{38}$ To restore the security shaken by

consistency of a proposition the correctness of the propoeition follows, that is, upon the (contentual) correctness of the principle of excluded middle» [76, p. 491].

33 Hilbert [32], in van Heijenoort [76, p. 381] (my emphasis).

34 See Brouwer [10]: «the differentiation between a construction of the 'inventory of mathematical formulas' and an intuitive (contentual) theory of the laws of this construction $\gg . .$. penetrated into the formalistic literature with Hilbert [30]». Brouwer mentioned that he spoke with Hilbert on that issue in the autumn of 1909 and hence he did not appreciate naming 'metamathematics', without «observing proper mention of authorship», what was, according to him, his notion of 'mathematics of the second order'.

35 Hilbert [31, p. 181] and Hilbert [32], in van Heijenoort [76, p. 385].

36 See the comments on Hilbert's metamathematical induction in the introductory note to Weyl's 1927 paper in van Heijenoort [76, pp. 480-482].

37 Hilbert [33], in van Heijenoort [76, p. 471].

38 Hilbert never spelled out the exact boundaries of finitistic means. However, Hilbert [31] mentioned explicitly induction and recursion on existing finite totalities. Hilbert [32] (in [76, pp. 377378] explained how to prove that there exist infinitely many primes by proving first the partial proposition: for a fixed prime $p$ there exists a prime $q$ such that $p<q \leq p$ ! +1 . In the latter proposition the existential quantifier is bounded (applied to a finite totality) and can be replaced by a finite disjunction. Hilbert's device here is similar to Skolem's method of restricted domains of existence (Skolem [55], in [76, pp. 302-333]). Sieg [54 pp. 28-29] shows that Hilbert's idea is 
the paradoxes and the attacks against the actual infinite, Hilbert saw no other way than a finitary consistency proof of the «ideal» picture of mathematics he constructed step by step.

b) Hilbert thought that it was necessary to consider the formal picture of customary mathematics. The reason is the following:

$\ll$... even elementary mathematics contains, first formulas to which correspond contentual communications of finitary propositions (mainly numerical equations or inequalities, or more complex communications composed of these) and which we may call the real propositions of the theory, and, second, formulas that - just like the numerals of contentual number theory - in themselves mean nothing but are merely things that are governed by our rules and must be regarded as the ideal objects of the theory. $\gg^{39}$

\section{Therefore, Hilbert fully assumed the formula game. He maintained that}

«the formula game enables us to express the entire thought-content of the science of mathematics in a uniform manner and develop it in such a way that, at the same time, the interconnections between the individual propositions and facts become clear. To make it a universal requirement that each individual formula then be interpretable by itself is by no means reasonable; on the contrary, a theory by its very nature is such that we do not need to fall back upon intuition or meaning in the midst of some argument». ${ }^{40}$

Moreover, Hilbert credited the formula game with a philosophical significance; he claimed that it expressed the «technique of our thinking». According to Hilbert, his proof theory provided «a protocol of the rules according to which our thinking actually proceeds $\gg .{ }^{41}$ This is clearly a mechanistic view of mathematical thought. $^{42}$

«strikingly similar to Weyl's viewpoint» in Weyl [79]. On his side, Zach [86] establishes (p. 220) that the general schema of primitive recursion was already mentioned in Hilbert's unpublished course of 1921-1923. Moreover, he argues that Hilbert's outlook was «markedly different» from Skolem's [55] (suggesting that there was no influence either way). Third, he challenges the generally admitted thesis, according which 'finitistic' means 'primitive recursive', stressing that Hilbert considered Ackermann's 1924 proof to be finitistic, although this proof used transfinite induction up to $\omega^{\omega^{\omega}}$ (I thank P. Mancosu for drawing my attention to Zach's paper).

${ }^{39}$ Hilbert [33], in van Heijenoort [76, p. 470] (Hilbet's emphasis, my underlining). Sieg [54] throws new light on this point. He quotes the following passage from Hilbert's notes for the winter term 1920: «We have to extend the domain of objects to be considered; i.e. we have to apply our intuitive considerations also to figures that are not number signs》 ... objects must be completely surveyable and only discrete determinations are to be considered for them. It is only under these conditions that our claims and considerations have the same reliability and evidence as in intuitive number theory».

${ }^{40}$ Hilbert [33], in van Heijenoort [76, p. 475].

${ }^{41}$ Hilbert [33], in van Heijenoort [76, p. 475].

${ }^{42}$ Contrast with Heyting [26], in Mancosu [44, p. 311]: «every language, including the formalistic one, is only a tool for communication. It is in principle impossible to set up a system of formulas which would be equivalent to intuitionistic mathematics, for the possibilities of thought cannot be reduced to a finite number of rules set up in advance». 
c) Hilbert did acknowledge that the validity of the principle of excluded middle was contentually limited to finite sets, ${ }^{43}$ but he sought the means to legitimately extend it to the transfinite. For this purpose he introduced the logical «transfinite axiom» by means of the tau or epsilon-function so that he could introduce the quantifiers and derive the principle of excluded middle. Thus, he used the epsilon-function to carry out pure existence proofs that he advocated once more, insisting on the brevity and the economy of thought they allow. Moreover, Hilbert noted that even if one were not satisfied with consistency, which actually constituted the core of his proof theory, one had to acknowledge the significance of the consistency proof as a general method of obtaining from general proofs finitary proofs carried out by means of the epsilon-function. ${ }^{44}$ This perspicuous remark inspired later a whole trend of proof-theoretic work, notably illustrated by some known papers of G. Kreisel. ${ }^{45}$

Concluding this rough sketch, I have to stress that I was concerned here only with aspects of Hilbert's work which may illustrate the formalist view he supposedly championed. I did not aim at supporting Brouwer's opposition to Hilbert, but at understanding what Brouwer meant by 'formalism' and to what extent Hilbert's methods and reflections matched the label Brouwer created. However, not only Hilbert's achievements transcended the boundaries of this label in many respects, but also the notion of formalism evolved so much as to not coincide at all with Brouwer's description.

\section{Tarski's Semantic Formalism}

\subsection{Metamathematics Reoriented}

Although he borrowed and transformed many technical elements and some views from each of the three standpoints: logicism, formalism and intuitionism, Tarski supported explicitly and exclusively the philosophy of none of them. Moreover, he repeatedly claimed he could develop his mathematical and logical investigations without reference to any particular philosophical view concerning the foundations of mathematics. He was eager to disconnect his results from any definite philosophical view, as well as from his personal (varied and variable) leanings. He believed that scientific precision was inversely proportional to philosophical interest, even though he had strong interest in philosophical issues.

\footnotetext{
${ }^{43}$ Hilbert [31], in Hilbert [36, pp. 181-182]. See Brouwer's comment in Brouwer [10].

${ }^{44}$ Hilbert [33], in van Heijenoort [76, p. 474].

${ }^{45}$ For instance Kreisel [40, p. 156]; Kreisel [41, pp. 361-362]; Kreisel [42, p. 162]: «As far as piecemeal understanding is concerned, its [Hilbert programme] importance consists of having led to the fruitful study of the constructive aspects of axiomatic systems ... My own interest ... does not go one way, i.e. the elimination of non-constructive methods, but I find that greater facility with non-constructive methods comes from a study of their constructive aspects».
} 
We are in front of a new fact in the history of modern mathematical logic: the nontacit and expressively assumed splitting between logical work as such, on the one hand, and, on the other hand, assumptions or beliefs about the effective or legitimate ways of doing that work and about the nature of the mathematical and logical entities linked with those ways.

Russell aimed to make philosophy as accurate as mathematics. Hilbert aimed to substitute mathematics to philosophy for tackling some important questions falling within the theory of mathematical knowledge - this was the epistemological aim of his metamathematics, which led him to the technicalities of his syntactic study of proof. ${ }^{46}$ Tarski wanted to separate logical results from ontological and epistemological problems of the foundations of mathematics, so that those results become easily understandable and usable by working mathematicians. He did not take sides in the fight about how to get mathematical entities well grounded and mathematical practice rightly justified. He was fighting for a new place for logic within mathematics, showing how to use fruitfully logical tools in the mathematical research. Solomon Feferman, who studied with Tarski at Berkeley from 1948 to 1957, testified that Tarski did have a very strong motivation, not only to make logic mathematical (Hilbert had the same aim, and before many logicians as well), «but also and at the same time to make it of interest to mathematicians $\gg .{ }^{47}$ This is why Tarski objected to restricting the role of logic to the foundations of mathematics. He always kept taking his initial aim, which was to make metamathematics a full mathematical field in its own right, like any other mathematical discipline, such as arithmetic or geometry. He claimed in a 1930 paper that «formalized deductive disciplines form the field of research of metamathematics roughly in the same sense in which spatial entities form the field of research in geometry». ${ }^{48}$ This claim of constituting metamathematics as a mathematical discipline was not fundamentally different from Hilbert's viewing Beweistheorie as a «new mathematics». And we may add that, in some respect, Tarski agreed with Hilbert's positivist claim, according to which «mathematics is a science without [philosophical] assumptions $\gg .{ }^{49}$ But while Hilbert kept investigating mathematical-logical foundations, in order to eradicate philosophical dogmatism and, eventually, to interpret Kant's a priori as the finite mode of thought, ${ }^{50}$ Tarski did not think he was (only) contributing to the

\footnotetext{
${ }^{46}$ Hilbert [32, p. 180]; in van Heijenoort [76, pp. 383-384]: «our proof theory ... is not only able to secure the foundations of the science of mathematics; I believe, rather, that it also opens up a path that ... will enable us to deal for the first time with general problems with fundamental character that fall within the domain of mathematics but formerly could not even be approached.» See also Bernays' comment: «The great advantage of Hilbert's procedure rests precisely on the fact that the problems and difficulties that present themselves in the grounding of mathematics are transferred from the epistemological-philosophical domain into the domain of what is properly mathematical. Mathematics here creates a court of arbitration for itself, before which all fundamental questions can be settled in a specifically mathematical way. .. 》, Bernays [5], in Mancosu [44, pp. 221-222].

47 See Duren [19, p. 402].

48 Tarski [58], in Tarski [70, I, p. 313].

${ }^{49}$ Hilbert [33 p. 85].

${ }^{50}$ Hilbert [34], in Hilbert [36, pp. 383-385].
} 
foundations of mathematics. He thought he was building a new mathematical branch on its own. Let us note, in passing, that the implicit epistemological attitude behind this thought was squarely opposed to the intuitionistic view according to which logic is extraneous to mathematical substance. The success of Tarski's enterprise came neither rapidly nor obviously. Still in 1955 Tarski was insisting on the bridge to be built or reinforced, in order to bring mathematicians close to logical methods. He and Leon Henkin wrote to E. Hevitt a letter (September 26, 1955) for supporting the idea of a summer institute on logic at Cornell University; they argued as follows:

«There are some mathematicians who are not familiar with the many directions in which this field [of logic] has recently developed. These mathematicians have the feeling that logic is concerned exclusively with those foundation problems which originally gave impetus to the subject; they feel that logic is isolated from the main body of mathematics, perhaps even classify it as principally philosophical in character. Actually such judgments are quite mistaken. Mathematical logic has evolved quite far, and in many ways, from its original form. There is an increasing tendency for the subject to make contact with other branches of mathematics, both as the subject and method. $\gg^{51}$

Indeed, Tarski strove to give logic a heuristic role in the growth of mathematical theories. As I pointed it out elsewhere, ${ }^{52}$ Tarski had no scruples about using formal methods and expanding them from mathematics to mathematical logic. It was he who initiated, in the 1930s, the heuristic shift in modern logic. A long time after the beginnings of this shift, Georg Kreisel commented as follows: «the passage from the foundational aims for which various branches of modern logic were originally developed to the discovery of areas and problems for which logical methods are effective tools ... did not consist of successive refinements ... but required radical changes of direction $\gg .53$

Thus, the heuristic shift reoriented the direction of foundational studies, breaking the hope that the latter would yield a final guarantee (Sicherung) of mathematical reasoning. Tarski thought that the aim to provide for mathematicians «a feeling of absolute security» was «far beyond the reach of any human science»; it pertained to «a kind of theology». ${ }^{54}$ Therefore, the non-theological aim of metamathematics was not to secure mathematics but to develop it. Tarski showed through some very significant examples, especially that of definable sets of real numbers, that metamathematics is nothing but just a new branch of $\ll$ ordinary» mathematics. ${ }^{55} \mathrm{He}$ stressed many times the following opinion:

«The distinction between mathematics and metamathematics is rather unimportant. For metamathematics is itself a deductive theory and hence, from a certain point of view, a part

\footnotetext{
51 Tarski's papers, Bancroft Library, quoted by Joseph W. Dauben [18, p. 233].

${ }^{52}$ Sinaceur [2], Part IV and Sinaceur [4, pp. 56-57].

${ }^{53}$ Kreisel [43, p. 139] (Kreisel's emphasis).

54 Tarski [73, p. 160].

55 It is today well known that the basic concept of real algebraic geometry, i.e. the concept of semialgebraic sets originates, conceptually if not through actual historical development, in Tarski's concept of definable sets of real numbers.
} 
of mathematics... Also from a practical point of view, there is no clear-cut line between metamathematics and mathematics proper». ${ }^{56}$

Tarski rejected also the clear-cut border that Hilbert put between the two connected fields, in order to neutralize Poincaré's criticism. ${ }^{57}$ But bringing metamathematics near to mathematics is bringing it far from philosophy. After Tarski, I will therefore distinguish the logic-mathematical level from the philosophical one. I propose to consider first Tarski's formalism in his mathematical and metamathematical practice, and to leave for a third part of this paper Tarski's philosophical considerations.

\subsection{Tarski's Version of Formalism}

To begin with, one must again highlight one significant fact. From the start of his career, Tarski was combining different technical ways which might have been judged previously incompatible.

I have noted this multi-sided methodology a long time ago. ${ }^{58} \mathrm{~J}$. Wolenski explains it as a consequence of the philosophical liberalism and the scientific ideology of the Warsaw School of logic.

«Since the school did not consider itself restricted by any philosophical assumption, it could freely observe the principle of 'logic for logic's sake' and take up, without any a priori prejudices, all those investigations that were interesting from the logical point of view». ${ }^{59}$

However, the general spirit of Tarski's logico-mathematical work was formalist, in a sense I shall explain right now.

a) First of all, Tarski adopted axiomatics and Hilbert's metamathematics, word and concept. However, the issue at stake was for him not only the structure of mathematical proof in a formal system, but rather the structure of the deductive theories $^{60}$ themselves, with a special eye on the most ancient and daily practiced mathematical domains, such as Euclidean geometry and real numbers. Tarski

\footnotetext{
56 Tarski [66], in Tarski [70, II, p. 693].
}

${ }^{57}$ Hilbert [30, p. 165]: Hilbert explained that he would develop a standpoint which makes possible «a strong and systematic separation, in mathematics, between formulas and formal proofs on the one hand and, on the other hand, contentual considerations $\gg$. Herbrand believed that the very strict distinction between mathematics and metamathematics would put an end to discussions on the foundations of mathematics, Herbrand [38, p. 39].

${ }^{58}$ H. Sinaceur [2, Part IV].

59 J. Wolenski [82, p. 192].

60 Tarski distinguished between deductive systems and deductive theories. See, for instance, Tarski [61], in Tarski [69, p. 343, footnote 1]: «By deductive theories I understand here the models (realizations) of the axiom system which is given in Section 1... On the other hand, deductive systems (in the domain of a particular deductive theory) are certain special sets of expressions which I shall characterize at the beginning of 1 as well as in Definition 5 of Section $2 \gg$. 
widened the scope of metamathematics, which no longer coincided with proof theory and the search for finitary consistency proofs. In his practice, he did not hesitate to use infinitistic and impredicative methods and he admitted first-order logic with infinitely long expressions, even though he actively participated in the early forties (with Carnap and Quine) to the endeavour to construct a finitistic language for science. ${ }^{61}$ Retrospectively, Tarski noted:

\begin{abstract}
$\ll$ As an essential contribution of the Polish school to the development of metamathematics one can regard the fact that from the very beginning it admitted into metamathematics all fruitful methods, whether finitary or not. Restrictions to finitary methods seem natural in certain parts of metamathematics, in particular in the discussion of consistency problems, though even here these methods may be inadequate. At present time it seem certain, however, that exclusive adherence to these methods would prove a great handicap in the development of metamathematics». ${ }^{62}$
\end{abstract}

b) Second, studying some deductive theory, Tarski paid attention to all the possible meanings of its axioms system. Confirming Lesniewski's idea, and therefore in connection with Husserl's phenomenology and the Vienna semantic tradition, Tarski used to stress that any formalized theory consists of meaningful sentences. Let us quote a famous passage from the Introduction to Logic:
$\ll$ From time to time one finds statements which emphasize the formal character of math- ematics in a paradoxical and exaggerated way; although fundamentally correct, these statements may become a source of obscurity and confusion. Thus one hears and even reads occasionally that no definite content may be ascribed to mathematical concepts; that in mathematics we do not really know what we are talking about, and that we are not interested in whether our assertions are true. One should approach such judgments rather critically. If, in the construction of a theory, one behaves as if one did not understand the meaning of the terms of this discipline, this is not at all the same as denying those terms any meaning. It is, admittedly, sometimes the case that we develop a deductive theory without ascribing a definite meaning to its primitive terms, thus dealing with the latter as with variables; in this case we say that we treat the theory as a FORMAL SYSTEM. But this situation (which was not taken into account in our general characterization of deductive theories given in Section 36) occurs only if it is possible to give several inter- pretations for the axiom system of this theory, that is, if there are several ways available of ascribing concrete meanings to the terms occurring in the theory, but if we do not desire to give preference in advance to any one of these ways. A formal system, on the other hand, for which we could not give a single interpretation, would presumably, be of interest to nobody. ${ }^{63}$

Such an explanation corresponds to the semantic shift in modern logic, which has been so much commented. Tarski did not initiate it from scratch, ${ }^{64}$ but he turned

\footnotetext{
${ }^{61}$ See the rich materials recently published by P. Mancosu [46].

${ }^{62}$ Contribution to the discussion of P. Bernays, Colloque International de Logique, Bruxelles, 1953, Revue Internationale de Philosophie 27-28 (1954), 18-19; in Tarski [70, IV, p. 713] (my emphasis).

63 Tarski [68, pp. 128-129].

${ }^{64}$ One source of the semantic shift is well identified by Wolenski's account: «Tarski grew up in a so-to-speak protosemantic atmosphere. The Lvov-Warsaw school was strongly influenced by the
} 
it into a heuristic shift. Tarski wanted indeed the formalization be closely tied to concrete interpretations and not lead too far from «ordinary» or $\ll$ normal» 65 mathematics, which used to make no reference to the syntax of the language.

c) Third, Tarski made a tight link between Hilbert's syntactic analysis of axiom systems and deductive proof on the one side and, on the other side, algebraic methods of logic as developed by Peirce, Schröder, Löwenheim and Skolem. ${ }^{66}$ As Feferman wrote, Tarski «would axiomatize and algebraicize whenever he could $\gg .{ }^{67}$ In and of themselves, algebraic methods involve the correlation of a formal aspect induced by the use of variables and a semantic aspect anchored in the many interpretations we may possibly give to the variables. 'Meaning' is thus specified as 'interpretation', i.e. as 'model'. In Tarski's development of semantic methods converged the philosophical-logical semantic tradition, which originated from Brentano, and the trend of algebraic logic. This trend and its interpretative aspect were in fact present in Hilbert's Foundations of Geometry and in his development of metamathematics [54]. But what has been specific in Tarski's own contribution was the study of the class of models (all possible models) of a given formal system, instead of considering only one definite model.

d) Fourth, Tarski aimed at constructing a general theory of semantic concepts in a formal deductive way. For instance, he notably axiomatized the consequence operation. Now, what basic concepts his formal semantics consisted in? In "Grundlegung der wissenschaftlichen Semantik" [63], he wrote the following:

\begin{abstract}
$\ll$ We shall understand by semantics ${ }^{68}$ the totality of considerations concerning the concepts which, roughly speaking, express certain connections between the expressions of a language and the objects and state of affairs referred to by these expressions. As typical examples of semantic concepts we may mention the concepts of denotation, satisfaction, and definition [...] The concept of truth - and this is not commonly recognized - is to be included here, at least in his classical interpretation, according to which 'true' signifies the same as 'corresponding with reality'.» ${ }^{69}$
\end{abstract}

Brentanist tradition ... [Brentano's] thesis that mental acts are intentional has in himself a semantic dimension. When Polish philosophers began to speak about names and sentences instead of presentations and judgments, this changed intentional relations into semantic ones, that is reference and truth. Moreover, the Brentano legacy decided that linguistic expressions were to be considered to be meaningful. This aspect of language almost automatically invited semantic studies.» Wolenski [84, pp. 10-11]. Another well known source was the development of mathematics, since at least the emergence of non-Euclidean geometries (for more see Webb [78]).

65 Tarski [60], English translation in Tarski 1983, p. 111.

66 Tarski's main technique, the elimination of quantifiers, is an outstanding example of the confluence of an usual practice of the algebra of logic with Hilbert's formulation of the decision problem. See the Introduction and the Notes 4, 5, 11, 21 of Tarski [64].

${ }^{67}$ Duren [19, p. 402].

68 See Wolenski's historical account: «The word 'semantic' became popular in philosophy in the thirties... .Poland was an exception in this respect. In the twenties Polish philosophers began to use the word 'semantyka' for considerations for the meaning-aspect of language.» Wolenski [84, p. 1] (my emphasis).

69 Tarski [63], in Tarski [69, p. 401]. 
It is clear that Tarski aimed at building a theory of reference, and not at a theory of meaning. 'Meaning' is not a semantic term in Tarski's formal semantics. ${ }^{70} \mathrm{We}$ have to keep in mind this fundamental feature, in order to understand correctly some consequences we shall discuss later.

e) Fifth, in studying deductive theories from the semantic point of view, one has therefore to study the semantics of formal systems. This study constituted a new direction of metamathematics. It consisted of examining the interconnections between syntactic properties of formal systems and mathematical properties of their models. The type of problems Tarski considered was the following:

\begin{abstract}
«Knowing the formal structure of axiom systems, what can we say about the mathematical properties of the models of the systems; conversely, given a class of models having certain mathematical properties, what can we say about the formal structure of postulate systems by means of which we can define this class of models? As an example of results so far obtained I may mention a theorem of G. Birkhoff (Proceedings of the Cambridge Philosophical Society 31, 1935, 433-454), in which he gives a full mathematical characterization of those classes of algebras which can be defined by systems of algebraic identities. An outstanding open problem is that of providing a mathematical characterization of those classes of models which can be defined by means of arbitrary postulate systems formulated within the first-order predicate calculus»..$^{71}$
\end{abstract}

As is well known, Tarski defined the concept of model $[62,63],{ }^{72}$ which was informally employed by many previous mathematicians and logicians. He paid attention to the relations of a language to its models and, inversely, of a class of models to a set of axioms able to express the formal theory of the class under consideration. This back-and-forth method between axioms systems and classes of models constituted Tarski's original way of practicing «conceptual analysis» for mathematical purposes, though it had been introduced and mainly used by modern logicians, notably by Frege, Russell, and Hilbert for foundational purposes. As a result of this new way of thinking, model theory came into being.

f) Sixth, as a further consequence of the semantic-heuristic shift he achieved, Tarski claimed that there was no universal formal language, no universal metatheory for the whole domain of mathematics. As early as 1930, he observed that «strictly speaking, metamathematics was not to be regarded as a single theory. For the purpose of investigating each deductive discipline a special metadiscipline should be constructed». This is contrary to the logicist view holding that logic is the universal metalanguage. Hilbert had assumed relativism within mathematics, since he

\footnotetext{
70 According to Quine's later account $\ll$ The main concepts in the theory of meaning, apart from meaning itself, are synonymy (sameness of meaning), significance (or possession of meaning) and analyticity (or truth in virtue of meaning). Another is entailment, or analyticity of the conditional. The main concepts in the theory of reference are naming, truth, denotation (or truth-of), and extension. Another is the notion of values of variables.» From a logical point of view, Cambridge (Mass), 1953, p. 130 (quoted after [84]).

${ }^{71}$ Contribution to the discussion of P. Bernays; in Tarski [70, IV, p. 714] (my emphasis) - The open problem is the definition of elementary classes, the solution of which will be given later through the method of ultraproducts.

${ }^{72}$ For a recent historical account of this concept in Tarski's work see Mancosu [47].
} 
stressed that a proof was relative to the chosen set of axioms for the theory under consideration. ${ }^{73}$ But, on the logical level, not only had Hilbert never explicitly disclaimed the view of (syntactic) logic as being the universal language, but he also suggested his own conception of proof theory should succeed where Frege's failed, since it aimed at giving a consistency proof for a formal system of arithmetic. We know that Gödel's second incompleteness theorem (1931) destroyed this aim, at least in the form and scope Hilbert ascribed to it. Developing semantic considerations and stating the distinction language/metalanguage as the king road to avoid antinomies led Tarski to a logical relativism, namely a semantic relativism: semantic concepts «must always be related to a particular language ${ }^{74}$ However and at the same time, Tarski thought that the concepts of logic penetrate the whole domain of mathematics and that the methodology of deductive sciences is «a general science of sciences». Logic, wrote Tarski, is «a discipline which analyzes the meaning of the concepts shared by all the sciences, and states the general laws ruling those concepts $\gg .{ }^{75}$ It is clear that logic is here not only a very fruitful tool for getting new mathematical results, but the tool «par excellence» for laying the basic laws of general semantic concepts which are involved in the analysis of deductive theories. This sounds like a kind of logicism, namely a semantic logicism, in comparison with Frege and Russell's syntactic logicism.

One may see a tension or even a conflict ${ }^{76}$ between Tarski's semantic relativism and his semantic logicism. And a similar tension exists also in respect to other issues on which Tarski, nearly at the same time or even in the same paper, ${ }^{77}$ sustained views seemingly not fully compatible with each other. For the point that we are now discussing, I think that the «tension-problem» has been resolved by Feferman's detailed analysis of the two sides of Tarski's efforts. ${ }^{78}$ Feferman argued that Tarski was first and foremost a mathematician and that he actually took a straightforward, though first informal, model-theoretic way since at least 1924; therefore he used the notions of definability and truth in a relative sense, as he undoubtedly did in his paper on the definable sets of real numbers (1931). On the other hand, «Tarski thought that as a side result of his work on definability and truth in a structure, he had something important to tell the philosophers that would straighten them out about the troublesome semantic paradoxes such as the

\footnotetext{
${ }^{73}$ Hilbert [30, p. 169]: «the concept 'provable' is to be understood as relative to the underlying axioms system. This relativism is in accordance with the nature of things and necessary.»

74 Tarski [63], in Tarski [69, p. 402].

75 Tarski 1960, p. XII (my emphasis, in order to stress that here Tarski meant not only the deductive sciences, but also the experimental sciences). The scope of logic is even wider, since Tarski aimed to create «a unified conceptual apparatus which would supply a common basis for the whole of human knowledge». See S. Feferman's comments in Feferman [23].

76 J. Wolenski [83, p. 331].

77 That happened at least twice: in Tarski 1960 and in Tarski [66], Sections 22 and 23.

${ }^{78}$ Feferman [22].
} 
Liar, by locating for them the source of those problems...»In the Wahrheitsbegriff (1933/36), according to Feferman, «we are not talking about truth in a structure but about truth simpliciter, as would be appropriate for a philosophical discussion, at least of the traditional kind». But the idea of a universal logical language is abandoned in the famous Postscript,${ }^{79}$ and, over time, Tarski qualified the logicist aspect of his first claims on the universality of logic. This is particularly clear in the way he answered the question 'What are logical notions?' [71], that we will discuss below (3.2 and Section 3.5). Moreover, Tarski always kept considering the whole domain of logic as a branch of «ordinary» mathematics and giving much evidence for his opinion through considerable work, even if he was willing to grant that the part of logic which is mathematics « does not perhaps exhaust logic $\gg .{ }^{80}$

Another example of how Tarski moved far from the logicist stance is his treatment of type theory. As we know, Tarski used, in an informal way, the language of the simple type theory in his early essays, for instance in the paper on the definable sets of real numbers and in the Wahrheitsbegriff. That certainly represented an acknowledgement of Russell's logical program. But, it is well known too that Tarski preferred set theory, with just one type of individual variables, and came to abandon type theory in favor of the latter. ${ }^{81}$ Therefore, he replaced logical universality with mathematical universality. It would be fine here to comment on F. Rodriguez-Consuegra's useful ramification of the concept of universality, which has been first suggested by Hintikka [39, pp. 13-15]. But, for my purposes, I need only to subscribe to the following point: on account of Tarski's footnote 2 to his Wahrheitsbegriff ${ }^{82}$ and of his 1995 posthumous paper, F. RodriguezConsuegra argues that Tarski regarded more and more the language of set theory as a mathematically universal language with one universal domain of individuals. ${ }^{83}$ It should just be added that Tarski regarded more and more the language of a sort of general algebra as fitting better his ambition to yield a universal language for mathematics, which would eliminate the current problems of set theory. $\mathrm{He}$ proposed already in 1953 a formalization of set theory without variables. ${ }^{84}$

\footnotetext{
${ }^{79}$ Feferman [22, p. 94]. While recognizing this fact, Feferman maintained for reasons that cannot be detailed here that, in the Wahrheitsbegriff, Tarski was after the concept of absolute truth (Feferman's emphasis and my underlining).

80 Tarski [74, p. 27] (my emphasis).

${ }^{81}$ See Carnap's account in Mancosu [46, pp. 335-336]: «The Warsaw logicians, especially Lesniewski and Kotarbinski saw a system like PM - Principia Mathematica - (but with simple type theory) as the obvious system form. This restriction influenced strongly all the disciples; including Tarski until 'The Concept of Truth' (where the finiteness of the level is implicitly assumed and neither transfinite types nor systems without types are taken into consideration; they are discussed only in the Postscript added later). Then Tarski realized that in set theory one uses with great success a different system form. So he eventually came to see this type-free system form as more natural and more simpler».

${ }^{82}$ English translation, Tarski [69, p. 210].

${ }^{83}$ F. Rodriguez-Consuegra [53]. See also Feferman [22, 23], and Hintikka [39].

${ }^{84}$ Tarski [70, IV, p. 605-606].
} 


\subsection{Tarski's Permanent Formal Leanings}

The most striking trait of the formal way of working is certainly the search for invariant elements under changing conditions. This is a typical method in algebra. Tarski applied it in semantics as well.

Tarski had indeed a permanent attraction for purely algebraic methods and their potential links with logical operations. He invested much work in the rigorous algebraic reformulation and generalization of classical theorems, e.g. Sturm's theorem (on how many real roots a polynomial has in a given interval) that he transformed into a quantifier elimination principle. ${ }^{85}$ - One has to point out, in passing, the finitistic character of this principle. - Tarski was also strongly interested in algebraic structures modeling logical operations, especially in Boolean algebras and cylindric algebras. He developed (together with Steven Givant) an algebraic approach to set theory which dispenses with variables: this general algebra was conceived of to provide a basic language for the whole field of mathematics. Algebra represented for Hilbert a paradigm for formal processing and extending the domain of surveyable objects. Tarski sought in it the means to avoid the logic of quantification. Hilbert introduced the transfinite axiom in order to justify the use of quantifiers, Tarski found out a mathematical device (Sturm's theorem) to eliminate quantifiers in the elementary theory of real numbers and Cartesian geometry.

3.1. A first example of Tarski's use of an invariant style is his semantic definition $^{86}$ of completeness: a theory is complete iff all its models are elementarily equivalent, i.e. iff a first-order sentence which is true in one model is also true in any other model of the theory. In other words, a theory is complete iff the set of first-order sentences that are proved in terms of one particular model remains invariant, so that one does not need to prove them again within another model. Tarski proved what was at his time an impressive result: the completeness of the first-order theory of real numbers and Cartesian plane geometry. As a consequence, he deduced that every first-order theorem about real numbers is already satisfied by algebraic real numbers. Thus, from a first-order logical point of view there is no difference between the field of algebraic real numbers, the underlying set of which is countable, and the field of real numbers, the underlying set of which is uncountable. This result may be considered as a corollary to Löwenheim's theorem that two nonisomorphic structures can be indistinguishable from the point of view of first-order logic (cardinality is neutralized). But Tarski shed a new light on it, presenting it as a logical invariance principle, which is weaker than algebraic isomorphism though none the shallower. Indeed, under the name 'transfer principle', it would have a great future and play a remarkable role not only in model theory, but also in some other mathematical branches: algebra, real algebraic geometry and analysis among others.

\footnotetext{
85 Tarski [64, 65] (see [2, Part I, II and IV]).

86 The syntactic definition is the following: a theory is complete iff every sentence of the language of the theory is provable or refutable. For first-order theories the two definitions are equivalent.
} 
Early on, Tarski aimed at constructing a general theory of the equivalence relation involved in this principle. The notion of elementary equivalence appeared in print in the appendix to the second part of 'Grundzüge des Systemenkalküls' [61]. Tarski was then aware that he opened up a wide realm of investigation, and he proposed to carry out with mathematical methods. Ten years later, closing his Address at the Princeton University Bicentennial Conference, Tarski put forward the notion and suggested again further study of the subject. Later on, he gave an outline of the theory of elementary classes [67] and elaborated, in collaboration with R. Vaught, the notion of elementary extension (1957).

3.2. A second well known example is his explanation of the notion of logical operation in the type structure over a basic domain of individuals. This is to be found in the posthumous paper edited by J. Corcoran [71], in which Tarski addressed the following question: «What are Logical Notions?». Tarski's procedure was to extend to the domain of logic Felix Klein's Erlanger Programm (1872) for the classification of geometries according to their invariant elements under some group of transformations. For instance, the notions of metric Euclidean geometry are those invariant under isometric transformations, the notions of projective geometry under projective transformations, etc. Tarski proposed to consider logic as an invariant theory ${ }^{87}$ and logical notions as those invariant in respect to any automorphism of the basic domain (any permutation of the domain) of the chosen universe of discourse. Considering a notion as logical depends on which formal language one chooses to define the term denoting this notion. Thus, if the formal language is that of type theory as developed by Whitehead and Russell in Principia Mathematica, then every notion is logical. Indeed, in this frame, set theory, within which the whole of mathematics can be constructed, is simply a part of logic, since the membership relation $(\epsilon)$ is invariant under the extension to higher types of any permutation of the domain of individuals. Thus, it appears that type theory was built in such a way as to justify logicist reductionism. Otherwise, if the language for formalizing set theory is Zermelo's first-order system - in which we have no hierarchy of types, but only one universe and the membership relation between individuals as a primitive term -, then mathematical relations are not logical. Indeed, the membership relation is not logical, since the only binary relations invariant under any permutation of the basic domain are the empty relation, the universal relation, the identity relation and its complement. ${ }^{88}$ Tarski concluded his essay stressing that the given definition did

${ }^{87}$ Feferman [20, footnote 5], noted that Tarski seems to have been unaware of the first proposal of that type by F. I. Mautner, An extension of Klein's Erlanger Programm: logic as invariant theory, American Journal of Mathematics 68 (1946), 345-384. On his side, P. Mancosu states in his recent paper [46] that the idea of using Klein's strategy was first suggested by Alexander Wundheiler on the ground of a method expounded by Tarski and Lindenbaum, Über die Beschränkheit der Ausdrucksmittel deduktiver Theorien, Erg. Math. Koll., VII (1936), 15-22. Wundheiler took part in the 10 January 1941 meeting, which was one of the series Tarski, Quine and Carnap had together during the academic year 1940-1941 at Harvard.

${ }^{88} \mathrm{~V}$. McGee showed that the logical operations in Tarski's sense are exactly those which are definable in the language $L_{\infty, \infty}$ : Logical operations, Journal of Philosophical Logic 25 (1996), 567580, quoted after Feferman [20]. Solomon Ferferman bases on McGee's result two objections. The 
not, in and of itself, imply a definite answer to the addressed question. Once again he emphasized that his logical work was free from any philosophical opinion, which naturally does not mean free from set-theoretic methods. Conversely, technical results did not, by themselves, settle philosophical questions connected with them. That is to say that, in Tarski's view, the connection between logic and philosophy is a one-to-many relation. Tarski's emphatic and persistent professed neutralism towards philosophical views and his pluralism (that Wolenski called «liberalism») match this kind of connection and suggest a rather positivist philosophical attitude.

If a characteristic way of formal thinking is first and foremost reasoning in terms of variables (having many possible meanings) and invariants (under such or such transformation), then Tarski was a very enthusiastic «formalist» mathematician, in a sense, however, which encompasses none of the three main features that Brouwer highlighted in his 1912 essay (see above 1.2). Tarski indeed dealt with meaningful sentences, understood consistency in the sense of satisfiability by a model, and alleged that he would not support a Platonistic existence for abstract entities. This apparently paradoxical result has a twofold explanation: (1) Tarski really provided formalism with a new substance, (2) Brouwer's influence really contributed, even if by no direct and not always acknowledged ways, to important aspects of the shift from a relatively dominant syntactic view to the alliance of syntax and semantics.

3.3. Early on, Tarski asserted that the union of syntax and semantics, that he initiated, could be «theoretically» placed under the spirit of Lesniewski's «intuitionistic formalism», ${ }^{89}$ while he claimed at the same time the independency of his technical achievements from any philosophical view. As it seems clear from the expression coined from the two previously contrasted terms, the «intuitionistic formalism», assumed as «an agreement in principle ${ }^{90}$ with Lesniewski's standpoint, might have been also a way to achieve the conciliation, initiated by Hilbert, between Brouwer's demand for contentual constructs and the formal processes of axiomatic and logic. That does not mean that Tarski accepted Brouwer's philosophical subjectivism, according to which one has to completely separate mathematics from language, especially from its description by logic, and to recognize mathematics as a «languageless activity of the mind having its origin in the perception of a move of time», ${ }^{91}$ which constitutes the basic Urintuition. Moreover, working to bring closer logic and «ordinary» mathematics, Tarski could not share the idea of a separate autonomy for each of the two domains, upon which Brouwer insisted.

\footnotetext{
first one is that Tarski assimilates logic to set-theoretical mathematics, what was indeed Tarski's own permanent aim. Second, Tarski failed to explain logicality across domains of different sizes. Feferman proposes a homomorphism invariance criterion to correct this failure. He also mentions the proof-theoretic approach of J.I. Zucker and R.S. Tragesser (The adequacy problem for inferential logic, Journal of Philosophical Logic 7 (1978), 501-516), which leads to characterize logical operations as exactly those of the first-order predicate calculus.

${ }^{89}$ Tarski [59], in Tarski [69, p. 62].

90 Tarski quoted the page 78 of S. Lesniewski, Grundzüge eines neuen Systems der Grundlagen der Mathematik, Sections 1-11, Fundamenta mathematicae 1 (1929), 1-81.

${ }^{91}$ Brouwer [13, p. 510].
} 
To stress the contrast with Brouwer's Urintuition, J. Wolenski replaced 'intuitionistic formalism' by 'intuitive formalism' in his account of Lesniewski's systems. ${ }^{92}$ Now, the word 'intuition' may rapidly induce a philosophical commitment, either to intuitionism - in a purely subjective option - or to Platonism if one holds that the subjective intuitive faculty is connected with an objective independent world or also to some kind of Kantian a priori as it was differently understood by mathematicians, for instance by Poincaré, Brouwer, Hilbert. But Tarski did not elaborate any specific theory of intuition. As Wolenski pointed out to me, Lesniewski and Tarski understood 'intuition' 'quite customary, namely as an ability to grasp contents (meaning)'. Therefore, it seems to me more appropriate to characterize Tarski's real way of working simply and merely as a semantic formalism, in opposition to the syntactic formalism shared by Frege, Dedekind and, to some extent, Hilbert. Those three hoped first and foremost to catch the entire content of a mathematical theory through a logical analysis of the syntactic properties of its fixed axioms system, while Tarski aimed at knowing under which logical conditions one can extend the content of a definite model of the theory.

Anyway, Tarski changed his mind: in a footnote added in 1956 in the English translation of his essay he pointed out that the «intuitionistic formalism» could no longer appropriately mirror his new attitude. What was no more convenient in this expression: 'intuitionistic', 'formalism' or both? Unfortunately, Tarski did not go so far as to positively describe what his new attitude was. Did Tarski keep silent because he separated philosophical thinking from scientific logical work? Certainly yes, even though there might have been other reasons.

\section{Tarski's Philosophical Pluralism}

Now, it becomes difficult to say that Tarski's explicitly assumed philosophical attitude matched the undoubtedly formal orientation of his practice. The path from the latter to the former is not straightforward. And that is not astonishing, since Tarski aimed to disconnect scientific reasoning from philosophical principles and, therefore, thought that a mathematical or logical technique made no philosophical point of view mandatory. Wolenski's judgment is right: it was not a problem for Tarski that his philosophical attitude did not fully agree with his own research practice in logic and mathematics. ${ }^{93}$ On the one hand, I do confirm the agreement between what I have called 'semantic formalism' and Tarski's actual practice. 'Semantic formalism' seems to me the right expression to characterize how Tarski actually worked. But, on the other hand, we have to take into account the following facts: (1) Tarski changed

\footnotetext{
92 Wolenski [82, p. 145]. According to Wolenski, Lesniewski was a «radical formalist in the sense of requiring an unambiguous codification of the language of a given formal system», but he firmly rejected the conception of logic and mathematics as a game of symbols devoid of meaning. More generally, the interpretative style of cultivating logic in the Warsaw School went back to Twardowski's tradition.

93 Wolenski [82, p. 192] (my emphasis).
} 
his mind and upheld, tacitly or explicitly, different philosophical attitudes without explaining the reasons of those changes. (2) Moreover, he used to propose on the same issue, at the same time, several options and to leave the choice open. This causes us a relative embarrassment. A way out is indeed to consider that Tarski was willing to construct arguments, not to give free rein to his belief. Therefore, he was trying different consistent arguments, as it was usual in the Ancient philosophicallogical tradition, at least in the part called 'dialectic' by Aristotle. Tarski's alleged philosophical neutrality was actually a real and very commendable philosophical option. In my view, it is perhaps the only tenable, though uncomfortable, option. After all, philosophical thinking is not just adapting argumentation to prior belief.

That being said, we still have the task to distinguish what Tarski claimed explicitly from what he did in fact, and to take into account the arguments he developed as dialectic exercices or, with a more modern scientific term, as 'Gedankenexperimente'. Grosso modo, one might say that, while he kept an anti-metaphysical general attitude (inherited from the Lvov-Warsaw School and strengthened by contacts with the Vienna Circle), Tarski stood on at the junction point of at least three views: a self-evident, though non-explicitly advocated, semantic realism, a strong logical nominalism with finitistic requirements, that he supported but moderately practiced, and an effective pragmatism, which finally permeated different levels of his thought.

\subsection{Tarski's Explicit Rejection of Ontological Realism}

Tarski's well known definition of truth is the classical one: truth as «correspondence» with reality. But what sense has to be given to «reality»? Tarski (1933) [66] rejected the realistic interpretation of his definition, in particular Gonseth's reproach of uncritical realism, i.e. of pre-Kantian realism. Tarski argued that classical formulations of the adequacy-relation between truth and reality, which are assumed to convey a realistic conception of truth, are neither precise nor clear enough. He preferred Aristotle's formulation, that he carefully recalled. ${ }^{94}$ And he recognized that his formal definition corresponded to the intuitive content of Aristotle's formulation. But he claimed that there was no necessary bound between his semantic definition and any of the following standpoints: realism, idealism, empiricism, metaphysical attitude. That means that Tarski did not base his semantic explanation on a priori or initial realistic (nor idealistic, nor empiricist nor metaphysical) assumptions; - if one seeks philosophical understanding, it would perhaps be better to go the other way around: to get a philosophical understanding, and probably not a one-sided one, from the scientific explanation. Tarski's explanation does not give a criterion to confront the sentence 'snow is white' to the real factual conditions under which we may affirm or not the sentence under consideration. The explanation shows the

$94 \ll$ To say of what is that it is not, or of what is not that it is, is false, while to say of what it is that it is, or of what it is not that it is not, is true». (Tarski [62], in Tarski [69, p. 155, footnote 2]). It is worth noting that Tarski pointed out (p. 153) that he set aside, for instance, the utilitarian conception, according to which 'true' reduces to 'useful'. 
equivalence between two sentences, traditionally referred to as the T-schema: the sentence 'snow is white' is true iff snow is white. Right to 'iff' we have a sentence and left to 'iff' we have the same sentence between quotation marks, i.e. we have the name of the sentence. We do not go out of the universe of discourse; we stay on a purely semantic level. The semantic definition states what truth is, not how to confirm or infirm it. Tarski meant that such a formal and non-effective definition needed not be backed up by a metaphysical or an epistemological conception. Semantics is indeed a scientific theory in its own right, and as a scientific theory it is supposedly philosophically neutral. Even if, with some right, one takes Tarski's claim concerning the neutrality of semantics cum grano salis, it should be taken for granted that Tarski rejected that pre-Kantian form of philosophical realism, which is also named 'essentialism' or 'ontological realism'.

\subsection{Tarski's Possible Acceptance of «a Moderate Platonism» and Actual Semantic Realism}

Tarski wrote indeed that he was never able to understand what is «the essence» of a concept. ${ }^{95}$ This means that a definition of a concept does not aim to capture, in a Platonist style, the essence of what is designated by the concept. Indeed, when Tarski set a definition for a notion (truth, logicality), he constantly insisted upon the fact that his definition, constructed within the frame of theoretic semantics, suited the effective meaning or use of the notion. Clearly enough this indicates that Tarski deliberately kept distance from Platon's way of constructing «essential» definitions.

But, Platonism does not only consist in the search for «essential definitions». It means also the belief in an ideal existence of the essences assumed to be the objects of such definitions, namely the belief in the autonomous existence of abstract entities.

Now, it is not a paradox to claim that a formal way of doing mathematics and logic may lead to some form of Platonism. We have seen above several degrees in the scale of Plato's assumptions analyzed by Bernays, the top of the scale being reached by set theory. For his part and on the one hand, Tarski used abstract methods and set-theoretic concepts involving infinitistic and non effective ways of reasoning. This might have implied a positive affirmation of the ideal existence of those abstract entities. But Tarski never committed himself to such an ontological statement. He did not admit the usual Platonistic understanding of the axioms of set theory, according to which sets exist independently of any human constructions. Moreover, he generally did not use predicate variables or higher types in his metamathematical analysis of mathematical theories, and he restricted himself to first-order language, in accordance with his algebraic bent, which led him to his quantifier

\footnotetext{
95 Tarski [66, Section 18).
} 
elimination technique. ${ }^{96}$ An interesting interpretation sees in Tarski's attitude an «as-if-realism», that is to say that Tarski mathematically behaved as if abstract entities existed, though his philosophical stand imposed restriction to individuals. ${ }^{97}$ This interpretation may have some loose connection with Tarski's acknowledgement in the discussion period for a 1965 meeting on the philosophical significance of Gödel's incompleteness theorems. ${ }^{98}$ Tarski said indeed that he, «perhaps in a 'future incarnation', would be able to accept a sort of moderate Platonism». In all likeliness Tarski said that he would accept a milder version of Gödel standpoint, which was an outright Platonism. This version could consist, for instance, in accepting only the sequence or the totality of natural numbers. ${ }^{99}$ Furthermore, Tarski meant he would «accept», not advocate.

On the other hand, the search for invariant principles might include the philosophical question about identity and persistence of some mathematical or logical content. For instance Tarski's transfer principle allows to transpose one and the same content from one model to another irrespective of the particular formal setting in which it is encapsulated. The transfer principle points out the persistency of a property, a meaning, through different formal frames. It is not a formal extension principle from intuitive operations to abstract ones ( $\ll$ formal permanency law» in the language of the XIXth century), but an extension of the same concrete meaning

\footnotetext{
${ }^{96}$ I did stress [2, Parts II and IV] the link between the idea of quantifier elimination and Hilbert's achievements, both on geometry where the aim was to determine the scope of the continuity axioms, the independency of which he proved through the construction of a non-Archimedean model, and on metamathematics, the goal of which was to check the consistency of formulas (ideal propositions) through the reduction of proofs to numerical equations or non-equations (real contentual propositions without variables).

97 See Rodriguez-Consuegra [53, p. 240]. The schema of an as-if attitude is already present in Hilbert [31, p. 187]: «In my proof theory it is not asserted that one can always effectively pick up an object among infinitely many objects, but that one can always, without risk of mistake, do as if the choice were made» (p. 187). See also Bernays [6], in Bernays [8, p. 60], in Mancosu [44, p. 262]: «The view at which we have arrived concerning the theory of the infinite can be seen as a kind of philosophy of the 'as if'. However, it differs entirely from the so-called philosophy of Vaihinger in the fact that it emphasizes the consistency and the stability [Beständigkeit] of the idea-formations... \. Mancosu [45, p. 316], noted that the same idea was previously developed by H. Behmann in his 1918 Dissertation (Hilbert was supervisor). The idea is still attractive for formalists. See Robinson [51], Selected Papers, II, p. 507: «My position concerning the foundations of Mathematics is based on the following two main points or principles. (i) Infinite totalities do not exist in any sense of the word (i.e. either really or ideally). More precisely, any mention, or purported mention, of infinite totalities is, literally, meaningless. (ii) Neverthelesss, we should continue the business of Mathematics 'as usual', i.e. we should act as if infinite totalities really existed» (Robinsons's emphasis).

98 Typescript of extemporaneous remarks during the discussion period for a symposium held in Chicago at a joint meeting of the Association of Symbolic Logic and the American Philosophical Association, 29-30 April 1965, Bancroft Library. Briefly quoted in Wolenski [83, p. 336]. A longer excerpt is quoted in Feferman [21, p. 61], and in Anita Burdman Feferman and Solomon Feferman [24, p. 52]. The topic is discussed at length in Rodriguez-Consuegra [53].

99 This interpretation matches the requirement Tarski imposed on the construction of a nominalistic language. See Mancosu [46, p. 336], quoted below.
} 
to other formal languages. In The completeness of elementary algebra and geometry [64], Tarski noted that, in order to determine whether or not a classical theorem of geometry belongs to his elementary formal system, «it is only the nature of the concepts, not the character of the means of proof that matters $\gg .{ }^{100}$ What Tarski highlighted here is that an elementary (first-order) theory may encompass concepts expressible or provable under non-elementary conditions, which are known to be satisfied in some particular model of the (complete) theory, for instance in real numbers. That is to say, a first-order theory may capture much more properties than first-order definable properties. From a logical (technical) point of view, this fact is, in and of itself, significant. From an epistemological point of view, this fact means that understanding a concept is not reducible to the technique of reasoning about it in some well-defined frame. Last but not least, from an ontological point of view, the insistence on a mathematical content independent of its formal definability or its proof has undoubtedly a Platonistic flavor, even if we cautiously distinguish 'nature' from 'essence'. But how «the nature» of a concept has to be understood? The reasonable answer in the frame of Tarski's mode of work seems to me the following: just as truth is not exhausted by deductive verification (Gödel's incompleteness theorem and Tarski's undefinability theorem), meaning is not exhausted by formal expression.

But again what is 'meaning'? This is a philosophical issue, which Tarski did not tackle. As we saw above, formal semantics did not comprise a theory of meaning. Wolenski pointed out that Tarski did once in 1936 made a remark on the subject in a discussion of a paper by M. Kokoszinska. ${ }^{101}$ Tarski simply observed that the concept of formal language was clearer and logically less complicated than the concept of meaning. But Tarski showed (notably trough the transfer principle) that meaning transcends formal language. This naturally leads to a realist view of meaning, in the same sense as the undefinability theorem leads to a realistic understanding of truth, in contrast with a constructive view. Now, as noted above, Tarski did reject the possibility of a logical link between semantic results and philosophical assumptions. He did reject metaphysical realism. Is there some real tension or, as Wolenski wrote some «cognitive dissonance $?^{102}$ I do not think so, at least concerning this specific

\footnotetext{
100 Tarski [70, IV, pp. 305-306] (my emphasis). The remark is repeated in the later in California published version [65], Tarski [70, III, p. 307].

${ }^{101}$ I thank Professor J. Wolenski for drawing my attention to this remark and for the translation of it from Polish; see Tarski [70, IV, p. 701]. The discussion took place in Krakow during the 3rd Polish Philosophical Congress after Kokoszynska's talk 'Concerning relativity and absoluteness of truth', and the translation of the remark is the following:

«It follows from the words of the speaker [that is, M. Kokoszynska - J. W.] among others things that the concept of truth - in one of its interpretations - should be relativized to the concept of meaning. Would not be simpler to relativize to the concept of language, which is clearer and logically less complicated than the concept of meaning?

Kokoszynska replied that the concept of language implicitly involves the concept of meaning. Hence, a double relativization should be made (1) to the stock of shapes or sounds; (2) to meaning».

102 Wolenski [82, p. 192].
} 
point. If we adopt Wolenski's distinctions between different kinds of realism, in particular between metaphysical realism and semantic realism, ${ }^{103}$ we may say that Tarski's views on truth and on mathematical concepts pertain to semantic realism, not to ontological realism. Moreover, as Wolenski showed, Tarski's semantic realism does not imply metaphysical realism, just as Tarski himself claimed. This explains why Tarski could uphold at the same time a realist attitude within the semantic sphere and a dislike of Platonism, which is, he thought, «unsatisfactory as an endpoint in philosophical analysis $\gg .{ }^{104}$

\subsection{Logical Nominalism}

In fact, Tarski invested a valuable amount of energy to avoid Platonism. - As for intuitionism or logicist reductionism he apparently felt no need to keep clear of them. - Influenced by Lesniewski and Kotarbinski, Tarski developed a strong nominalistic bent. It is worth recalling that nominalism emerged in the Middle Ages in the debate about universals and particulars. According to Mycielski [48], Tarski was familiar with this debate through Twardowski's book Six Lectures on Medieval Philosophy and with the distinctions between nominalism, Platonism and conceptualism. To clarify things, I recall a brief characterization. Nominalists admitted only the existence of particulars. Conceptualists admitted the existence of concepts or forms, especially when the universals were represented in individuals. Platonists admitted the existence of concepts and forms independent of human mind. What distinguished conceptualists from nominalists is that they did not reduce concepts to mere signs or names: concepts were contentual operations of thought; then, their existence was understood as a thought-existence. What distinguished conceptualists from Platonists is that they did not detached the existence of concepts from the operating thought: concepts did not exist on their own, prior to thought, they did not play the role of the essences of empirical things. ${ }^{105}$ In the view of this tripartition, it seems to me that one could consider conceptualism as very near to semantic realism, despite the fact that Tarski spoke neither of conceptualism nor of semantic realism. His concern was to stress his opposition to Platonism. Indeed, Tarski described himself as a nominalist. In the typescript of the remarks at the 1965 symposium on Gödel's incompleteness theorems, Tarski said:

103 Wolenski [85, pp. 135-148]. Wolenski defines semantic realism by the fact or supposition that meaning transcends use. Here I assume that semantic realism means also that meaning transcends language.

104 Quoted by Mancosu [46, pp. 334, 348].

105 We may note, in passing, that Hilbert's and Bernays' designation of Platonism as «conceptual realism» was literally adequate. 
$\ll \mathrm{I}$ happen to be, you know, a much more extreme anti-Platonist. ... I represent this very crude, naïve kind of anti-Platonism, ${ }^{106}$ one thing which I could describe as materialism, or nominalism with some materialistic taint, and it is very difficult for a man to live his whole life with this philosophical attitude, especially if he is a mathematician, especially if for some reason he has a hobby which is called set theory... 》

Thus, Tarski avowed himself the tension between his philosophical views and his mathematical needs. And he maintained this duality (which supports the «as-ifPlatonism» interpretation). Later on indeed, at the closing of his seventieth birthday symposium (1976), Tarski said:

$\ll \mathrm{I}$ am a nominalist. This is a very deep conviction of mine. It is so deep, indeed, that even after my third reincarnation, I will still be a nominalist. ... People have asked me, 'how can you, a nominalist, do work in set theory and logic, which are theories you do not believe in?'... I believe that there is value even in fairy tales and the study of fairy tales». ${ }^{107}$

This might be interpreted as a joke. But a joke is also an usual way not to give one's last word on some issue.

In fact, there is a deep connection between Tarski's professed nominalism and his actual formal practice, which was strongly impregnated with an algebraic spirit. Tarski would have probably not disapproved Brouwer's judgment, according to which abstract entities exist only «on paper». Working in set theory does not necessarily mean believing in a hypostastic existence of sets. After all, it is possible to deal with concepts without reifying them, i.e. without transforming them into «real» objects, «real» being interpreted either as having a material character through concatenations of signs or as a Platonist universe of timeless objects. But, was it not Tarski's aim to disconnect the semantic sphere, to which mathematical concepts belong, from the ontological one and, therefore, at eliminating unnecessary ontological suppositions? Naturally 'yes', and we have even stressed that semantic realism does not necessarily entails ontological realism.

Nevertheless, we need, I think, to have an idea of the philosophical status that Tarski might have attributed to meaning, which he used as an informal notion. From the model-theoretic point of view, 'meaning' is 'interpretation' or 'realization' (and truth is equivalent to the existence of a model). Now, there are interpretations with infinite basic domains. Then, in Tarski's mind, what would have been the satisfactory philosophical final view on interpretations/meanings of the abstract theories, i.e. his final view on abstract entities? Might Tarski have accepted, in accordance with the formalist tradition, abstract entities as beautiful and fruitful fictions («fairy tales»), something similar to Leibniz differential operator or to Hilbert's ideal elements, the justification of which is the ultimate reduction to finite entities? If the answer were 'yes', then Tarski's position would result in a combination of

106 See also Mycielski [48, p. 217]: in 1970 Tarski mentioned to Mycielski «the Platonic belief of Gödel that sets can be seen (seen, not imagined) in our minds almost like physical objects», and added that this belief «is bewildering».

107 Anita Burdman Feferman and Solomon Feferman [24, p. 52]. Also Mycielski [48, p. 216]: «Tarski told me that he is a nominalist». 
nominalism and finitism. As we shall see in the next paragraph, some evidence is now available for associating Tarski's nominalism with finitism.

But, from the philosophical point of view, has Tarski really thought that meaning belongs to the world of fairy tales? Was meaning, in Quine's words, a myth? Would Tarski have agreed with Quine's reductionism, and would he have ultimately admitted an elimination of meaning in favor of its linguistic medium, that he found clearer? I do not think so, because accepting the linguistic reduction of meaning would tip the whole enterprise of formal semantics into a mere linguistic analysis, what it is not. Then, might Tarski have considered meaning as a mental act or process? A positive answer to this question would lead him near either to the medieval conceptualism or to modern intuitionism. But, on the basis of the available evidence relative to his cultural background, we cannot suppose that Tarski would have accepted to go Brouwer's road. On the other hand, Tarski did not express himself about conceptualism. Then the question of what acceptable philosophical status could be given to meaning from Tarski's point of view remains open.

Now, how can we understand Tarski's alliance of nominalism with materialism in his claim at the Chicago meeting? On Wolenski's account, ${ }^{108}$ nominalism and materialism (physicalism) were typical of Kotarbinski's reism. Wolenski thinks that Tarski was much more attracted to reism than Mostowski admitted ${ }^{109}$ and he suggests understanding materialism as being an empiricism. Tarski stressed indeed that between logical and empirical statements $\ll$ there is only a mere gradual and subjective distinction ${ }^{110}$ and that logical sentences might be just as revisable as the factual ones. ${ }^{111}$ Thus, we have necessarily to take into account a «time coefficient» and to refer any hypothesis to a given historical stage of the development of a science. This empiricist basic option sheds substantial light on Tarski's nominalism and make a bridge with the logical empiricism of the Vienna Circle, but does not answer the question why fairy tales keep being attractive. In other words, how is it possible to reconcile semantic realism with logical nominalism?

\subsection{Nominalism, Finitism, Constructivism}

Linked with his professed nominalism, Tarski upheld two other views, as we newly became aware through P. Mancosu's work on an important set of notes found in Carnap's Nachlass in Pittsburgh, the edition of which is being prepared by Greg Frost-Arnold. Carnap reported indeed that, during the Fall of 1940, he regularly met Quine and Tarski at Harvard, and discussed with them on the construction of a finitistic mathematical language for science. This language was intended to be

\footnotetext{
108 Wolenski [82, Chapter XI].

109 A. Mostowski, Tarski, Alfred, The Encyclopaedia of Philosophy, 8, P. Edwards ed., 1967, New York, Macmillan, 77-81; Wolenski [83, footnote 2, p. 340].

110 Quoted in Mancosu [46, p. 328].

111 Tarski [72].
} 
type-free: P. Mancosu highlights the shift that was taking place in Tarski's thought (and in logic in general) from type-theoretic to first-order languages.

In developing their project Carnap, Quine and Tarski agreed on three points: the language should be nominalistic, (weakly) finitistic and constructivistic. It is worth quoting after Mancosu the whole passage [46, p. 336]:

\begin{abstract}
$\ll \ldots$ We agreed that the language must be nominalistic, i.e., its terms must not refer to abstract entities but only to observables objects or events. Nevertheless, we wanted this language to contain at least an elementary form of arithmetic. To reconcile arithmetic with the nominalistic requirement, we considered among others the method of representing the natural numbers by the observable objects themselves which were supposed to be ordered in a sequence; thus no abstract entities would be involved. We further agreed that for the basic language the requirements of finitism and constructivism should be fulfilled in some sense. Quine preferred a very strict form; the number of objects was assumed to be finite and consequently the numbers occurring in arithmetic could not exceed a certain maximum number. Tarski and I preferred a weaker form of finitism, which left open whether the number of all objects is finite or infinite. Tarski contributed important ideas on the possible forms of finitistic arithmetic.»
\end{abstract}

First of all, one notes that here 'nominalism' is understood in its medieval sense: only particulars were admitted. No mention was made of the modern sense given to the term by members of the Vienna Circle, especially Carnap, who advocated the view that mathematics is reducible to some syntax of language. I guess Tarski would not have supported this view. Nevertheless, the material published by P. Mancosu shows the driving role Tarski played in these discussions and the influence he had in the early development of twentieth century analytic philosophy.

Second, as Mancosu stresses, no clear distinction was made in the Carnap's notes between nominalism and finitism. On 10 January 1941, Tarski unfolded his view on finitism ${ }^{112}$ by stating that he basically «understood» only languages, which satisfy the following conditions: finite (later on, he also allowed for infinite) number of individuals, the individuals are physical things (Kotarbinski's reism), there are no variables for universals (classes and so on), i.e. there is no Platonic assumption. Tarski brought a precision, which seems to me important, because it makes very clear how pivotal were his algebraic leanings. He added indeed: «Other languages I 'understand' only the way I 'understand' [classical] mathematics, namely as a calculus». This is an explicit acknowledgement of one of the basic views Tarski had from the beginning of his work: even if it was not until the 1950s that model theory flourished as a discipline in its own right, the model-theoretic view of mathematical language as an reinterpretable calculus has been permanently present in Tarski's mind and practice from the beginnings of his work. This algebraic view did not totally preclude the opposite view of set-theoretic language as a universal mathematical language. But it became more and more prominent, so that it led to the project of a general algebra as fundamental base for the whole mathematics. This

112 Mancosu [46, p. 343]. 
project has been embodied in his posthumous book (together with Steven Givant): A Formalization of Set Theory without Variables. ${ }^{113}$

Now, one may wonder whether «the method of representing the natural numbers by the observable objects themselves which were supposed to be ordered in a sequence» really dispenses with the set of natural numbers, which is involved, at least potentially, in the notion of sequence. But for Tarski the distinction between potential and actual infinity was not an essential one. ${ }^{114}$ The main problem for him was whether logic and mathematics, which are «an indispensable tool for scientific research in empirical science $\gg \ldots \ll$ «an be constructed or interpreted nominalistically». ${ }^{115}$ Since he wanted to have elementary arithmetic, Tarski suggested to reformulate Peano's axioms so that no axiom of infinity is included and to construct a recursive arithmetic. ${ }^{116} \mathrm{He}$ also chose a constructive definition of elementary arithmetic.

\title{
3.5 Effective Pragmatism or the Final View on Meaning
}

In his early period, Tarski sometimes and somehow defended the intrinsic interest of metamathematical research. For instance, he declared the following:

\begin{abstract}
«Being a mathematician (as well as a logician, and perhaps a philosopher of a sort), I have had the opportunity to attend many discussions between specialists in mathematics. . .I do not wish to deny that the value of a man's work may be increased by its implications for the research of others and for practice. But I believe, nevertheless, that it is inimical to the progress of science to measure the importance of any research exclusively or chiefly in terms of its usefulness and applicability. We know from the history of science that many important results or discoveries have had to wait centuries before they were applied in any field. And, in my opinion, there are also other important factors which cannot be disregarded in determining the value of a scientific work. It seems to me that there is a specific domain of very profound and strong human needs related to scientific research, which are similar in many ways to aesthetic and perhaps religious needs. ${ }^{117}$
\end{abstract}

But, at the same time, Tarski repeatedly stressed the independence of his technical results from any philosophical assumption and their mathematical usefulness. It seems to me that over time Tarski came closer and closer to the outlook most fitting the scientific practice in general, namely a pragmatist outlook. By pragmatism I understand here simply an attitude primarily determined by the ways and needs of actual mathematical practice. Pragmatism rests upon the primacy given to use, but does not necessarily entails utilitarianism, which says that 'true' is nothing more than 'useful'.

\footnotetext{
113 Tarski and Givant [75].

114 Mancosu [46, p. 345].

115 Letter to Woodger, 21 November 1948, quoted by Mancosu [46, p. 347].

116 For more see Mancosu, pp. 350-354.

117 Tarski [66], Tarski [70, II, p. 693].
} 
Indeed, from the 1950s onward, much as an «ordinary» mathematician, he raised the question of applicability of metamathematical methods in a very straightforward manner. In particular he strove to show that his theory of elementary classes «had good chances to pass the test of applicability ... [and to] be of general interest to mathematicians $\gg .{ }^{118}$ On many other occasions, Tarski professed taking the practice into consideration, especially when he aimed to set a precise definition for a notion, the meaning of which has been previously vague or understood only in an informal way. One of the constraints he placed upon the definition is that it has to match the mathematical or logical use. Defining itself may be just setting criteria for using the notion. Thus, in the above quoted lecture 'What are logical notions?', Tarski explained that answers to questions such as the one he addressed may be of different kinds. In some cases, one may give an account of the prevailing usage of the expression denoting the definiendum: this is a descriptive definition. In other cases, one may set criteria for future usage, relatively independent from the current usage: this is proposing a normative definition. Tarski claimed to have set in his paper a normative definition, namely to have suggested a possible use for the expression 'logical notion'. This possible use fits the mathematical use, which originates from Klein's outstanding procedure to distinguish various systems of geometry. Anyway, be it actual or potential, usage keeps to be one of the basic conditions that the construct of a definition must satisfy. Moreover, Tarski explicitly added that the aim of «catching the proper, true meaning of a notion, something independent of actual usage, and independent of any normative proposals, something like the platonic idea behind the notion $\gg$ constituted, to his eyes, «so foreign and strange an approach», so that he would simply ignore it. Now, may one not infer from this passage and from some other brief remarks including those on the concept of definable sets of real numbers [60], ${ }^{119}$ on the semantic definition of truth $[62,66]$ that I have quoted above, and on the characterization of semantic concepts ${ }^{120}$ that, in Tarski's philosophical final view, meaning was use?

Whatever the answer to this question might be and so surprising the union of pragmatism and semantic realism might seem, the gradually more salient role of usage in Tarski's thought and practice, as well as his basic and permanent motivation to making logic useful for the working mathematician, allows one to claim that Tarski's effective philosophical attitude was in keeping with a kind of pragmatism. All fruitful methods are welcome, he thought and wrote. The study of fairy tales is worthwhile, because they can be submitted to experiments so that they gain a firm

\footnotetext{
118 Tarski [67], Tarski [70, III, p. 473].

119 English translation, Tarski [69, p. 112]: «We then seek to construct a definition. . which, while satisfying the requirements of methodological rigour, will also render adequately and precisely the actual meaning of the term ['definable set of real numbers']».

120 Tarski [63], in Tarski [69, p. 402]: «the task of laying the foundations of a scientific semantics, i.e. of characterizing precisely the semantical concepts and of setting up a logically unobjectionable and materially adequate way of using these concepts, presents no further insuperable difficulties [as soon as we take into account the relative character of these concepts]» (my emphasis).
} 
ground in our culture and they manifestly are «very useful and very helpful in the development, in the progress achieved $\gg$ [by mathematics, therefore by physics and other sciences]. ${ }^{121}$ They provide with important results, either theoretic ones, which permit a better intrinsic understanding of the subject under consideration, or technical ones which can be applied, through physics, to the external world. As a helpful means of investigation, fairy tales do not contravene empiricism and, precisely because we are aware that they lack reality, they are compatible with nominalism. Last but not least, fairy tales satisfy inescapable human needs. ${ }^{122}$

\section{Conclusion}

I used in this paper expressions such as 'semantic formalism', 'semantic relativism', 'semantic logicism', 'semantic realism'. Those expressions, which may seem at first sight either surprising or finally trivial, must not be taken as a mere trick. Actually, they are stressing again and again that Tarski's fundamental aim was to establish formal semantics as a new branch of metamathematics. As a consequence of his aim, Tarski was constantly highlighting the semantic aspect of any method he adopted and any view he defended, and he was also constantly concerned with establishing the scientific autonomy of formal semantics. He contributed mostly to develop by rigorous means and to let largely known the interpretative style of the Polish School of logic.

Thus, while developing formal methods in this interpretative style, Tarski was greatly concerned with the idea of keeping close to mathematical practice and of holding non-dogmatic philosophical views. He was willing to experiment different, and even opposite, ways of constructing mathematical and logical theories. According to Steven Givant, Tarski very early developed an experimental style of working. In particular, the seminar on mathematical logic conducted by Lukasiewicz, to which he participated in the years 1920-1924, was viewed as «a kind of logicomathematical laboratory where [the participants] could conduct experiments in assessing the expressive and deductive powers of various theories $\gg .{ }^{123}$ Much later, Tarski claimed to be «quite interested in attempts at constructing set theory on the basis of some non-classical logics, simply as an experiment. We shall see to what it will lead». ${ }^{124}$ «Try and see» seems to have been a guiding principle of his logico-mathematical experimentation, and it was thus natural to make many different attempts with no a priori expectation of the result. In a fundamentally empiricist and pragmatic way, Tarski managed to blend nominalism, which is the philosophical counterpart of a finitistic requirement, which in its turn matches his empiricistic or

\footnotetext{
121 Quoted by Rodriguez-Consuegra [53, p. 248].

122 Compare with Weyl 1925-1927, in Mancosu [44, p. 141]: «there is a theoretical need, simply incomprehensible from the merely phenomenal point of view, with a creative urge directed upon the symbolic representation of the transcendent, which demands to be satisfied».

123 Givant [25, p. 52].

124 Typescript of Tarski's contribution at the 1965 Chicago meeting. Quoted by F. RodriguezConsuegra [53, p. 250].
} 
physicalistic fundamental perspective, with a semantic realism, which is needed not only to develop beautiful theories, but also to support the semantic view that truth is not just proof, and meaning not just language. If one stands on this view at a philosophical level, then one has to pay the price for it, and the least one is just not to accept the reduction of truth or meaning to something else, whatever it might be. But, if, practically, i.e. for the working mathematician, showing the truth is nothing but proving some assertion and if meaning is only use, in accordance with rules (already established or to be formulated), then pragmatic considerations become primary, even in the study of the world of fairy tales.

Acknowledgments I am grateful to Jan Wolenski and to Paolo Mancosu for useful comments on a previous draft of this paper and for drawing my attention to some references. I thank also Sten Lindström and the referee for many improvements.

\section{References}

1. Benacerraf P. and Putnam H. 1983, Philosophy of Mathematics. Selected Essays, Prentice Hall, Inc. Englewood Cliffs, New Jersey (first ed. 1964).

2. Benis Sinaceur Hourya. 1991, Corps et Modèles, Essai sur l'histoire de l'algèbre réelle, Paris, Vrin (second ed. 1999).

3. Benis Sinaceur Hourya. 1993, Du formalisme à la constructivité: le finitisme, Revue Internationale de Philosophie 47, n 186, 4/1993: 251-284.

4. Benis Sinaceur Hourya. 2001, Alfred Tarski: Semantic Shift, Heuristic Shift in Metamathematics, Synthese 126: 49-65.

5. Bernays P. 1922, Über Hilberts Gedanken zur Grundlegung der Arithmetik, Jahresbericht der Deutschen Mathematiker-Vereinigung 31: 10-19. English translation in Mancosu 1998, 215-222.

6. Bernays P. 1930, Die Philosophie der Mathematik und die Hilbertsche Beweistheorie, Blätter für Deutsche Philosophie 4: 326-367. Reprinted in P. Bernays 1976, 17-61. English translation in Mancosu 1998, 234-265.

7. Bernays P. 1935, Sur le platonisme en mathématique, L'enseignement mathématique, XXIV, $\mathrm{n}^{\text {os }}$ 1-2: 52-69. Reprinted in P. Bernays, Philosophie des mathématiques, Paris, Vrin, 2003, 83-104. English translation in Benacerraf P. and Putnam H. 1983, 274-286.

8. Bernays P. 1976, Abhandlungen zur Philosophie der Mathematik, Darmstast, Wissenchaftliche Buchgesellschaft. French translation, Paris, Vrin, 2003.

9. Brouwer L.E.J. 1912, Intuitionism and Formalism, Bulletin of the American Math. Society 20: 81-96. Reprinted in Brouwer 1975, 123-137.

10. Brouwer L.E.J. 1928, Intuitionistische Betrachtungen über den Formalismus, Koninklijke Akademie van wetenschappen te Amsterdam, Proceedings of the Section of Sciences 31: 374379. Reprinted in Brouwer 1975, 409-414. English translation of $\S 1$ in van Heijenoort 1967, 490-492.

11. Brouwer L.E.J. 1929, Mathematik, Wissenschaft, und Sprache, Monatshefte für Mathematik 36, 153-164. Reprinted in Brouwer 1975, 417-428. English translation in Mancosu 1998, 45-53.

12. Brouwer L.E.J. 1948, Consciousness, Philosophy, and Mathematics, Proceedings of the Tenth International Congress of Philosophy, Amsterdam, 1948. Reprinted in Brouwer 1975, 480-494.

13. Brouwer L.E.J. 1952, Historical Background, Principles and Methods of Intuitionism, South Africa Journal of Science, Cape Town, July 1952. Reprinted in Brouwer 1975, 508-515.

14. Brouwer L.E.J. 1975, Collected Works I, A. Heytind (ed.), North-Holland. 
15. Cantor G. 1966, Abhandlungen mathematischen und philosophischen Inhalts, Hildesheim, Georg Olms Verlagsbuchhandlung, 1966.

16. Dedekind R. 1888, Was sind und was sollen die Zahlen?, Braunschweig, Vieweg.

17. Dedekind R. 1890, Letter to Keferstein, 27 February 1890, English translation in Jean van Heijenoort (ed.), 1967, 98-103.

18. Dauben J.W. 1995, Abraham Robinson, Princeton, Princeton University Press.

19. Duren P. 1989, A Century of Mathematics in America, Part III, American Mathematical Society, Providence R.I., 393-403.

20. Feferman S. 1999a, Logic, Logics, and Logicism, Notre Dame Journal of Formal Logic 40: $31-54$.

21. Feferman S. 1999b, Tarski and Gödel: Between the Lines, in Tarski J. and Köhler E. (eds.), Alfred Tarski and the Vienna Circle. Austro-Polish Connections in Logical Empirism, Dordrecht/Boston/London, Kluwer Academic Publishers, 53-64.

22. Feferman S. 2003, Tarski's Conceptual Analysis of Semantical Notions, in A. Benmakhlouf (ed.), Sémantique et épistémologie, Casablanca, Editions Le Fennec, 2003, 79-108.

23. Feferman S. 2004, Tarski's conception of logic, Annals of Pure and Applied Logic 126: 5-13.

24. Feferman A. and Feferman S. 2004, Alfred Tarski: Life and Logic, Cambridge, Cambridge University Press.

25. Givant S. 1999, Unifying Threads in Alfred Tarski's Work, The Mathematical Intelligencer 21(1), 47-58.

26. Heyting A. 1930, Die formalen Regeln der intuitionistische Logik, Sitzungsberichte der Preussischen Akademie der Wissenschaften, Phys.-Math. K1. 42-56. English translation in Mancosu 1998, 311-327.

27. Hilbert D. 1899, Grundlagen der Geometrie, Zehnte Auflage, Stuttgart, B. G. Teubner, 1968.

28. Hilbert D. 1905, Über die Grundlagen der Logik und der Arithmetik, Verhandlungen des dritten Mathematiker-Kongresses (Heidelberg, August 1904), Leipzig, B.G. Teubner.

29. Hilbert D. 1918, Axiomatisches Denken, Mathematische Annalen 78: 405-415; in Hilbert $1935,146-156$.

30. Hilbert D. 1922, Neubegründung der Mathematik. Erste Mitteilung, Abhandlungen aus dem Mathematischen Seminar der Hamburgischen Universität 1, 155-177; in Hilbert 1935, 155-177. English translation in Mancosu 1998, 198-214.

31. Hilbert D. 1923, Die logischen Grundlagen der Mathematik, Mathematische Annalen 88: 151-165; in Hilbert 1935, 178-191.

32. Hilbert D. 1926, Über das Unendliche, Mathematische Annalen 95: 161-190. English translation in van Heijenoort 1967, 367-392.

33. Hilbert D. 1928, Die Grundlagen der Mathematik, Abhandlungen aus dem Mathematischen Seminar der Hamburgischen Universität 6: 65-83. English translation in van Heijenoort 1967, 464-479.

34. Hilbert D. 1930, Naturerkennen and Logik, Naturwissenschaften 18: 959-963; in Hilbert $1935,378-387$.

35. Hilbert D. 1931, Die Grundlegung der elementaren Zahlenlehre, Mathematische Annalen 104: 485-494.

36. Hilbert D. 1935, Gesammelte Abhandlungen III, Berlin, Springer. Reprint New York, Chelsea, 1965.

37. Hilbert D. and Bernays P. 1934, Grundlagen der Mathematik I, Berlin, Springer-Verlag.

38. Herbrand J. 1968, Écrits Logiques, van Heijenoort (ed.), Paris, Presses Universitaires de France.

39. Hintikka J. 2004, On Tarski's Assumptions, Synthese 142: 353-369.

40. Kreisel G. 1958, Mathematical Significance of Consistency Proofs, The Journal of Symbolic Logic 23: 155-182.

41. Kreisel G. 1968, A Survey of Proof Theory, The Journal of Symbolic Logic 33: 321-388.

42. Kreisel G. 1983, Hilbert's Programme, Dialectica 12 (1958): 346-372. English expanded version in Benacerraf P. and Putnam H. 1983, 207-238. 
43. Kreisel G. 1985, Mathematical Logic: Tool and Object lesson for Science, Synthese 62: $139-151$.

44. Mancosu P. 1998, From Brouwer to Hilbert. The Debate on the Foundations of Mathematics in the 1920s, New York, Oxford University Press.

45. Mancosu P. 1999, Between Russell and Hilbert: Behmann on the Foundations of Mathematics, The Bulletin of Symbolic Logic 5(3): 303-330.

46. Mancosu P. 2005, Harvard 1940-1941: Tarski, Carnap and Quine on a finitistic language of mathematics for science, History and Philosophy of Logic 26 (November 2005): 327-357.

47. Mancosu P. 2006, Tarski on Models and Logical Consequence, in Ferreirós J. and Gray J.J. (eds.), The Architecture of Modern Mathematics, Chapter 7, Oxford University Press (forthcoming).

48. Mycielski J. 2004, On the Tension Between Tarski's Nominalism and His Model Theory (Definitions for a Mathematical Model of knowledge), Annals of Pure and Applied Logic 126: 215-224.

49. Poincaré H. 1905, Les mathématiques et la logique, Revue de Métaphysique et de Morale 13: 815-835 and 14: 17-34.

50. Reid C. 1970, Hilbert, New York-Heidelberg-Berlin, Springer-Verlag.

51. Robinson A. 1965, Formalism 64, Proceedings of the International Congress for Logic, Methodology and Philosophy of Science, Jerusalemn (1964), Amsterdam, North Holland, 228-246; in H.J. Keisler, S. Körner, W.A.J. Luxemburg and A.D. Young (eds.), Selected Papers, New Haven/London, Yale University Press, 1979, 505-523.

52. Robinson A. 1969, From a formalist's point of view, Dialectica 23: 45-49.

53. Rodriguez-Consuegra F. 2005, Tarski's Intuitive Notion of Set, in Sica G. (ed.), Essays on the Foundations of Mathematics and Logic, Monza (Italy), Polimetrica International Scientific Publisher, Advanced Studies in Mathematics and Logic, 1: 227-266.

54. Sieg W. 1999, Hilbet's Programs: 1917-1922, The Bulletin of Symbolic Logic 5(3): 1-44.

55. Skolem T. 1923, Begründung der elementaren Arithmetik durch die rekurrierende Denkweise ohne Anwendung scheinbaren Veränderlichen mit unendlichem Ausdehnungs-bereich. English translation in van Heijenoort 1967, 302-333.

56. Suppes P. 1988, Philosophical Implications of Tarski's Work, The Journal of Symbolic Logic 53(1): 80-91.

57. Tait W. 1981, Finitism, The Journal of Philosophy 78(9): 487-546.

58. Tarski A. 1930a, Über einige fundamentale Begriffe der Metamathematik, Compte Rendus de la Société des Sciences et des Lettres de Varsovie XXIII, Cl. 3: 22-29. Reprinted in Tarski 1986a, I, 311-320. English translation in Tarski 1983, 30-37.

59. Tarski A. 1930b, Fundamentale Begriffe der Methodologie der deduktiven Wissenschaften I, Monatshefte für Mathematik und Physik, 37: 361-404. Reprinted in Tarski 1986a, I, 341-390. English translation in Tarski 1983, 60-109.

60. Tarski A. 1931, Sur les ensembles définissables de nombres réels I, Fundamenta Mathematicae 17: 210-239. Reprinted in Tarski 1986a, I, 517-548. English translation in Tarski 1983, $110-142$.

61. Tarski A. 1935-36, Grundzüge des Systemenkalküls I, II, Fundamenta Mathematicae 25: 503-526 and 26: 283-301, in Tarski 1986a, II, 25-50 and 223-244. English translation in Tarski 1983, 342-383.

62. Tarski A. 1936a, Der Wahrheitsbegriff in den formalisierten Sprachen, Studia Philosophica I: 261-405 (first publication in Polish in 1933). English translation in Tarski 1983, 152-278.

63. Tarski A. 1936b, Grundlegung der wisenschaftlichen Semantik, Actes du Congrès International de Philosophie Scientifique, Paris, Hermann, 1936, 1-8, in Tarski 1986a, II, 259-268. English Translation: The Establishment of Scientific Semantics, Philosophical and Phenomenological Research 4 (1944): 341-376, in Tarski 1983, 401-408.

64. Tarski A. 1939/67, The Completeness of Elementary Algebra and Geometry, Paris, Institut Blaise Pascal; in Tarski 1986a, IV, 289-346. 
65. Tarski A. 1948/51, A Decision Method for Elementary Algebra and Geometry (prepared for publication by J.C. McKinsey), University of California Press, Berkeley and Los Angeles. In Tarski 1986a, III, 297-368.

66. Tarski A. 1944, The Semantic Conception of Truth and the Foundations of Semantics, in Tarski 1986a, II, 661-699.

67. Tarski A. 1952, Some Notions and Methods on the Borderline of Algebra and Metamathemtics, Proceedings of the International Congress of Mathematicians (Cambridge, Mass. 1950), Providence, American Mathematical Society, 705-720. Tarski 1986a, III, 459-476.

68. Tarski A. 1965, Introduction to logic and to the Methodology of the Deductive Sciences, New York, Oxford University Press (first edition, 1941).

69. Tarski A. 1983, Logic, Semantics, Metamathematics, Papers from 1923 to 1938 translated by J.H. Woodger, Oxforfd, Clarendon Press (first ed. 1956).

70. Tarski A. 1986a, Collected Papers I, II, III, IV, Givant S.R. and McKenzie R.N. (eds.), Birkhäuser.

71. Tarski A. 1986b, What are Logical Notions, Posthumous Paper edited by Corcoran J., History and Philosophy of Logic 7: 143-154.

72. Tarski A. 1987, A Philosophical Letter of Alfred Tarski, with a prefatory note by Morton White (1944), Journal of Philosophy 84: 1987, 28-32.

73. Tarski A. 1995, Some Current Problems in Metamathematics, Posthumous Paper edited by Tarki J. and Wolenski J., History and Philosophy of Logic 16: 159-168.

74. Tarski A. 2000, Address at the Princeton University Bicentennial Conference on Problems of Mathematics (December 17-19, 1946), Posthumous Paper edited by H. Benis Sinaceur, The Bulletin of Symbolic Logic 6(1): 1-44.

75. Tarski A. and Givant S. 1987, Formalization of Set Theory without Variables, American Mathematical Society, Providence, R.I.

76. Van Heijenoort J. 1967, From Frege to Gödel. A Source Book in Mathematical Logic, 1879-1931, Cambridge (Mass.), Harvard University Press.

77. Webb J.C. 1980, Mechanism, Mentalism, and Metamathematics, Dordrecht-Boston-London, D. Reidel Publishing Company.

78. Webb J.C. 1995, Tracking Contradictions in Geometry: The Idea of a Model from Kant to Hilbert, in J. Hintikka (ed.), From Dedekind to Gödel. Essays on the Development of the Foundations of Mathematics, Synthese Library, vol. 251, Dordrecht/Boston/London, Kluwer Academic Publishers, 1-20.

79. Weyl H. 1921, Über die neue Grundlagenkrise der Mathematik, Mathematische Zeitschrift 10: 39-79. English translation in Mancosu 1998, 86-118.

80. Weyl H. 1925-27, Die heutige Erkenntnislage in der Mathematik. English translation in Mancosu 1998, 123-142.

81. Weyl H. 1928, Diskussionsbemerkungen zu dem zweitem Hilbertschen Vortrag über die Grundlagen der Mathematik, Abhandlungen aus dem Mathematischen Seminar der Hamburgischen Universität 6: 86-88. English translation in van Heijenoort 1967, 480-484.

82. Wolenski J. 1989, Logic and Philosophy in the Lvov-Warsaw School, Synthese Library, vol. 198, Dordrecht/Boston/London, Kluwer Academic Publishers.

83. Wolenski J. 1995, On Tarski's Background, in J. Hintikka (ed.), From Dedekind to Gödel. Essays on the Development of the Foundations of Mathematics, Synthese Library, vol. 251, Dordrecht/Boston/London, Kluwer Academic Publishers, 331-342.

84. Wolenski J. 1999, Semantic Revolution. Rudolf Carnap, Kurt Gödel, Alfred Tarski, in Tarski J. and Köhler E. (eds.), Alfred Tarski and the Vienna Circle. Austro-Polish Connections in Logical Empirism, Dordrecht/Boston/London, Kluwer Academic Publishers, 1-15.

85. Wolenski J. 2003, Logic, Semantics and Realism, in A. Benmakhlouf (ed.), Sémantique et épistémologie, Casablanca, Editions Le Fennec, 2003, 135-148.

86. Zach R. 2003, The Practice of Finitism: Epsilon Calculus and Consistency Proofs in Hilbert's Program, Synthese 137: 211-259. 
Chapter-15

\begin{tabular}{|c|c|c|c|}
\hline Query No. & Page No. & Line No. & Query \\
\hline AQ1 & 355 & 42 & $\begin{array}{l}\text { Shall we change the quotes "« } \\
\ldots . . \gg \text { " to double quotes throughout } \\
\text { this chapter? }\end{array}$ \\
\hline AQ2 & 374 & 15 & $\begin{array}{l}\text { "Tarski } 1960 \text { " present in the foot note } \\
\text { has not been listed in the reference } \\
\text { list, please provide. }\end{array}$ \\
\hline AQ3 & 391 & 19 & $\begin{array}{l}\text { This reference has not been cited in } \\
\text { the text part, please provide. }\end{array}$ \\
\hline AQ4 & 391 & 21 & $\begin{array}{l}\text { This reference has not been cited in } \\
\text { the text part, please provide. }\end{array}$ \\
\hline AQ5 & 392 & 20 & $\begin{array}{l}\text { This reference has not been cited in } \\
\text { the text part, please provide. }\end{array}$ \\
\hline AQ6 & 393 & 09 & Please update. \\
\hline AQ7 & 393 & 18 & $\begin{array}{l}\text { This reference has not been cited in } \\
\text { the text part, please provide. }\end{array}$ \\
\hline AQ8 & 393 & 27 & $\begin{array}{l}\text { These references has not been cited in } \\
\text { the text part, please provide. }\end{array}$ \\
\hline
\end{tabular}

